\title{
Enzymatic Targets in Atherosclerosis
}

\section{Elena V Fuior, Violeta G Trusca, Corina Roman and Anca V Gafencu* \\ Institute of Cellular Biology and Pathology, Nicolae Simionescu, Bucharest, Romania}

*Corresponding author: Anca V Gafencu, Institute of Cellular Biology and Pathology, Nicolae Simionescu, 8, B. P. Hasdeu Street, POB 35-14, Sect 5, 050568 Bucharest, Romania, Tel: +4-021-3192737/222; Fax: +4-021-3194519; E-mail: anca.gafencu@icbp.ro

Received date: June 15, 2015; Accepted date: July 20, 2015; Published date: July 27, 2015

Copyright: (c) 2015 Fuior EV, et al. This is an open-access article distributed under the terms of the Creative Commons Attribution License, which permits unrestricted use, distribution, and reproduction in any medium, provided the original author and source are credited.

\begin{abstract}
Atherosclerosis, a prime cause of mortality across the developed societies, was targeted by diverse therapeutic strategies. These evolved in response to the complex etiology and evolution of the disease. Many enzymes are associated with atherosclerosis, either in the main stream of lipid biosynthesis and transport or in the collateral and intertwined pathways of oxidative stress, inflammation, vascular remodeling or chromatin stability and are therefore revised herein. Enzyme exploration led to important developments. At the beginning, there were the statins, derived as inhibitors of hydroxy-methyl-glutaryl CoA (HMG-CoA) reductase, currently used widely to decrease lipid levels. At the other end, the inhibitors of the recently discovered proprotein convertase subtilisin/kexin type 9 (PCSK9) are awaiting the validation in clinical trials with great hopes for the future. In between, one can find some palliatives, as aspirin, an inhibitor of cyclooxygenase (COX), but also many invalidated candidates. Classical pharmacological data and newer approaches, like genetic knockouts in murine atherosclerosis models, are reviewed in order to appreciate the involvement of a particular enzyme in atherogenesis. However, the pursuit of an efficacious drug has been long and, in many cases, disappointing. Conclusions can be drawn from the overview of both successes and failures, in a quest for the best.
\end{abstract}

Keywords: Atherosclerosis; apoE; Therapeutic target

\begin{abstract}
Abbreviations
ACAT: Acyl-Coenzyme A-Cholesterol Acyltransferase; apoB: Apolipoprotein B; apoCI: Apolipoprotein CI; apoE: Apolipoprotein E; CAT: Catalase; COX: Cyclooxygenase; DNMT: DNA Methyltransferases; FTase: Farnesyltransferase; GGTaseI: Geranylgeranyltransferase I; GPx: Gluthation Peroxidase; HDAC: Histone Deacetylases; HDL: High-Density Lipoprotein; HMGCR: 3Hydroxy-3-Methyl-Glutaryl-CoA Reductase; HO: Heme Oxygenase; IFN $\gamma: \gamma$ Interferon; LCAT: Lecithin-Cholesterol Acyltransferase; LDL: Low-Density Lipoprotein; LDLR: Low-Density Lipoprotein Receptor; LO: Lipoxygenase; Lp-PLA2: Lipoprotein-Associated Phospholipases A2; LPS: Lipopolysaccharide; miRNA: microRNA; MMP: Matrix Metalloproteinase; NFkB: Nuclear Factor KB; NO: Nitric Oxide; NOS: Nitric Oxide Synthase; oxLDL: Oxidized LDL; PCSK9: Proprotein Convertase Subtilisin/kexin type 9; PON: Paraoxonase; ROS: Reactive Oxygen Species; SMase: Sphingomyelin Phosphodiesterase; SMCs: Smooth Muscle Cells; SMS: Sphingomyelin Synthase; SOD: Superoxide Dismutase; SPT: Serine Palmitoyltransferase; SQS: Squalene Synthase; TNFa: Tumor Necrosis Factor a; VLDL: Very Low-Density Lipoprotein
\end{abstract}

\section{Introduction}

Atherosclerosis continues to remain the leading medical, social and economic challenge in the developed societies. Atherosclerosis occurs primarily as a result of the accumulation of cholesterol in the arterial wall, upon which subsequent events of calcification and inflammation lead to the formation of a characteristic plaque which reduces the blood vessel lumen. In the advanced stages, the plaque can be destabilized and obstruct blood flow, with lethal consequences.

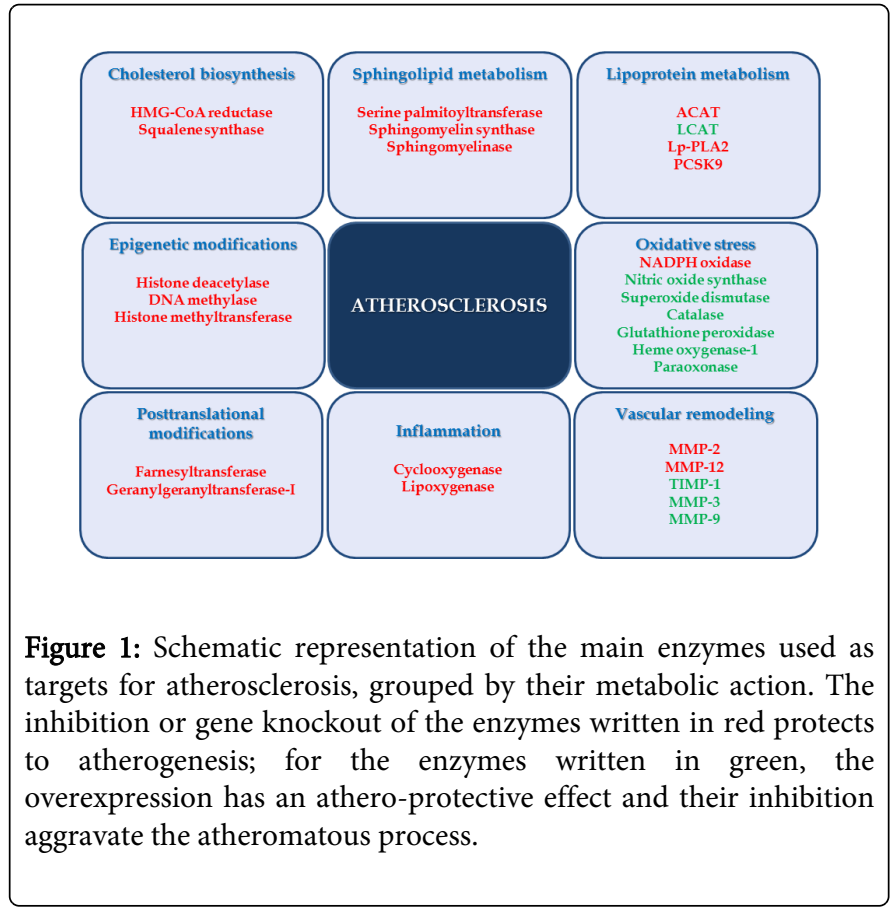

Despite great research developments, the contemporary life style and genetic heritage afflict millions of individuals and their number raises. Due to the multifactorial, multistage manifestation of the disease, atherosclerosis was approached from different points of view, from which very diverse therapeutic strategies emerged. Most of them aimed lipid lowering as a primary therapeutic target, while others targeted later events to delay the progression of the disease, alleviating its phenotype. The current status of the most promising approaches, 
either in use or in advanced clinical trials, have been recently reviewed by others $[1,2]$. The focus of the current paper was to summarize contemporary studies addressing the roles of various enzymes implicated in atherosclerosis, the rationale for targeting them, the main experimental models utilized, the challenges encountered, the puzzling/ controversial/ unexpected results. A diverse assortment of enzymes is presented (Figure 1), without any pretense of being exhaustive. This outline reflects the current status of both experimental and theoretical progresses, with an emphasis on the atherosclerotic murine knockout models, supplemented by pharmacological data.

From the multitude of the data overviewed below, unfortunately very few had come to a positive therapeutic end, of which the most well-known are statins. Others, like the novel PCSK9 (proprotein convertase subtilisin/kexin type 9) inhibitors, are expected with enhanced interest. In the same time, numerous inhibitors have proved to be at least ineffective, if not deleterious. More reflection and the development of new targeting and delivering strategies may help.

\section{Cholesterol Biosynthesis Related Enzymes}

\section{HMG-CoA reductase}

HMG-CoA reductase (3-hydroxy-3-methyl-glutaryl-CoA reductase, HMGCR) catalyzes the conversion of HMG-CoA to mevalonic acid, dependent on NADH (EC 1.1.1.88) or NADPH (EC 1.1.1.34) and controls cholesterol biosynthesis [3], as illustrated in Figure 2. Therefore, this enzyme is the target of the widely available cholesterollowering drugs known as statins, originally developed to competitively inhibit the binding of HMG-CoA to HMG-CoA reductase and to reduce mevalonate synthesis [4]. Statins lower LDL-cholesterol levels more dramatically than other lipid-lowering agents, and they also exert pleiotropic effects, including anti-inflammatory, anti-thrombotic and antioxidant effects $[5,6]$. The former statins, such as lovastatin, pravastatin, simvastatin, are derivatives of fungal products, while newer statins, including atorvastatin, cerivastatin, fluvastatin, rosuvastatin are synthetic. In various clinical trials involving patients with hypercholesterolemia, rosuvastatin and atorvastatin induced greater decreases in LDL-cholesterol than the other statins tested [7]. Despite that statins have been shown to be efficient in clinical trials and they are now commonly used for hyperlipidemia, they cannot completely eradicate the risk for cardiac heart disease $[8,9]$. Apart from the beneficial effects of statin therapy, the development of myopathies [10], side effects on hepatic and renal function [11], diabetes mellitus [12], as well as cognitive dysfunctions [13] were reported, with higher occurrence for lipophilic statins (atorvastatin, lovastatin, simvastatin), and lower prevalence for hydrophilic statins (pravastatin, rosuvastatin). However, the overall benefit for cardiovascular disease through statin therapy still exceeds the risk of side effects. Excepting cerivastatin, which was withdrawn because of severe myopathy and rhabdomyolysis, the tolerability of statins was similar. An earlier comprehensive review summarized the clinical benefits of statin therapy in wide-ranging cardiovascular disorders, such as acute coronary syndrome, cardiac arrhythmias, heart failure, peripheral arterial disease, cerebrovascular disease, as well as hypertension [14]. A plethora of studies [15] demonstrated that regression of atherosclerotic plaque does occur with statin therapy, and it was estimated that an average of two years of aggressive statin therapy was required for this regression to take place.

\section{Squalene synthase}

Squalene synthase (farnesyl-diphosphate farnesyl transferase; FDFT1; SQS; EC 2.5.1.21) catalyzes the two step NADPH-dependent reductive dimerization of two $\mathrm{C} 15$-farnesyl pyrophosphate moieties with the formation of the C30-cholesterol precursor squalene, as illustrated in Figure 2. Squalene synthase is localized exclusively to the membrane of the endoplasmic reticulum [16]. Ablation of SQS in mice is lethal, the enzyme being essential for the development of the central nervous system [17]. Increased expression of SQS has been shown to elevate cholesterol levels in mice [18]. The reaction catalyzed by SQS occurs beyond the branching point of isoprenoid biosynthesis, being the first committed step in cholesterol synthesis. Thus, it was expected that SQS pharmacological targeting would be an attractive approach for the treatment of atherosclerosis due to reduced side effects. To this aim, various SQS inhibitors were assessed for their capacity of lowering cholesterol level [19]. Among these, the benzoxazepine derivative lapaquistat acetate (TAK-475) seemed the most promising. In animal studies on WHHLMI rabbits, a model for coronary atherosclerosis and myocardial infarction, TAK- 475 slowed down the progression of coronary atherosclerosis and changed the coronary atheromatous plaques from an unstable, lipid-rich to a stable, fibromuscular phenotype [20]. In humans, administration of TAK-475, alone or together with statins, significantly reduced lowdensity lipoprotein (LDL)-cholesterol in a dose-dependent manner. It also decreased other risk markers, such as C-reactive protein. However, its hepatotoxic effects such as raised levels of aminotransferase and bilirubin, led to the termination of advanced clinical trials [21]. For an extensive review of SQS inhibitors as antiatherosclerotic agents, the reader is directed to the recent comprehensive review of Kourounakis [19].

\section{Sphingolipid Metabolism Related Enzymes}

Sphingolipids are essential constituents of the plasma membrane, key signaling molecules and modulators of plasma lipoprotein metabolism [22]. A preference for cholesterol association with sphingolipids in the plasma membrane lipid raft microdomains is believed to serve as a signal transduction centers for immune responses, which may be important for the inflammatory component of atherogenesis [23]. Plasma sphingomyelin (SM) emerged recently as a risk factor for cardiovascular diseases [24], being a key regulator of plasma lipoprotein metabolism and atherosclerosis [25]. Recently sphingolipids have been attributed a rather active role in cardiovascular pathology, since inhibition of their de novo synthesis raises anti-atherogenic lipoproteins and decreases atherosclerosis in murine models [26]. Thus, genetic and pharmacological interventions on the enzymes involved in sphingolipid biosynthetic pathways open a new avenue for therapeutic approaches in this field.

\section{Serine palmitoyltransferase}

Serine palmitoyltransferase (palmitoyl-CoA:L-serine Cpalmitoyltransferase (decarboxylating); SPT; EC 2.3.1.50) catalyzes the condensation between palmitoyl-CoA and L-serine, the first reaction in sphingolipid biosynthesis. In eukaryotes the enzyme is anchored to the endoplasmic reticulum [27] and it consists of a dimer of SPTLC1 and SPTLC2 or SPTLC3 [28] or it could aggregate in even higher oligomers [29]. SPTLC1 or SPTLC2 knockout in mice embryos is lethal, while heterozygous animals (Sptlc1(+/-), Sptlc2(+/-)) are viable, but present a modified plasma lipid profile. Thus, they exhibit decreased plasma sphingolipid levels, but no change in plasma 
triglyceride, total cholesterol, phospholipids, plasma and liver sphingomyelin [30]. SPT is specifically inhibited by the fungal antibiotic myriocin [31]. Treatment with myriocin of apoE-deficient mice led to reduced levels of plasma sphingolipid, increased level of phosphatidylcholine, but similar cholesterol or triglyceride level, while an substantial decrease of the size of the atherosclerotic lesions was noticed [32,33]. The anti-atherosclerotic effect was due to the decreased level of sphingolipids, but not of glycosphingolipids, since EtDO-P4, a glucosylceramide synthesis inhibitor, had no impact on the lesion area [34]. In other studies, myriocin treatment of apoEdeficient mice was reported to lower plasma cholesterol and triglyceride levels in a dose-dependent manner, to reduce VLDL- and LDL- cholesterol, to increase HDL-cholesterol, and to enhance the level of apoAI and LCAT in the liver [26]. Recently, a series of miRNAs have been shown to control $\beta$-amyloid level by regulation of SPT levels, providing a link between the upregulation of SPT and sporadic Alzheimer's disease [35]. Therefore, there is still enough therapeutic potential to be explored by inhibiting SPT.

\section{Sphingomyelin Synthase}

Sphingomyelin synthase (ceramide:phosphatidylcholine cholinephosphotransferase; SMS; EC 2.7.8.27) catalyzes the last step of SM de novo biosynthesis, through the reaction between ceramide and phosphatidylcholine, with the formation of sphingomyelin and 1,2 diacylglycerol. Two SMS genes, SMS1 and SMS2, have been cloned and characterized [36]. The proteins differ by their localization, with human SMS1 in the Golgi apparatus and SMS2 at the plasma membrane, and they also exhibit different tissue expression profile. SMS role in cell survival can be appreciated by the fact that it consumes the pro-apoptotic ceramide, while generating the antiapoptotic diacylglycerol. SMS2 overexpression in apoE-deficient mice correlated with an enhanced endothelial dysfunction and aggravated atherosclerotic plaque instability [37]. Hepatic SMS2 is essential for plasma SM level regulation, as demonstrated with SMS2-deficient and SMS2 liver-specific transgenic mice. Thus, SMS2-deficient mice had decreased SM levels, while the transgenic animals overexpressing SMS2 had increased SM level. Additionally, atherogenic lipoproteins from the transgenic mice displayed a significantly stronger tendency toward aggregation after treatment with mammalian sphingomyelinase, compared with controls. Moreover, SMS2 knockout significantly raised plasma apoE level, whereas liver-specific SMS2 overexpression decreased it. Plasma of SMS2-deficient mice promoted cholesterol efflux from macrophages, whereas plasma of SMS2 transgenic mice prevented it [38]. SMS2 deficiency attenuates the activation of the pro-atherogenic factor NF- $\mathrm{kB}$, as proved in murine SMS2 knockout macrophages mice exposed to lipopolysaccharide (LPS) and in SMS2 siRNA-treated HEK-293 cells exposed to TNF a [39]. Another group reported that SMS2/apoE double knockout mice showed a significant decrease in aortic atherosclerotic lesions [40]. Also, transplantation of bone marrow alone from SMS2 knockout mice into LDLR-deficient mice led to a reduction of atherosclerosis [41]. However, in macrophages, SMS2 seems to be responsible only for less than $20 \%$ of the total SMS activity. SMS1 is responsible for most SMS activity of macrophages and is capable of rescuing growth of SMS2-deficient murine lymphoid cells [42]. SMS1 knockout mice have significantly decreased level of sphingomyelin and highly increased levels of glucosylceramide and GM3 in the plasma, liver, and macrophages, an effect not seen for SMS2 deficiency. As for SMS2 knockout, SMS1 deficiency attenuated LPS-induced Nk-FB activation and SMS1-deficient mice bone marrow transplantation into LDLR-deficient mice led to a reduction of atherosclerosis [43]. Recent data showed that, besides the alteration in lipid profile, SMS1 null mice exhibited increased pro-atherogenic oxidative stress [44]. Despite the valuable data accumulated via genetic manipulation of Sms genes, the pharmacological approaches lagged behind. Only recently, small molecule SMS inhibitors in the micro molar range that could be used in atherogenesis or related pathologies as insulin resistance, were described [45]. Pharmacological reduction of SMS has also proved that SMS could be a target of anti-atherogenic therapy. Dy105, a SMS inhibitor, reduced SM levels in SM-rich microdomains on cell membranes, decreased apoB secretion in a human hepatoma cell line and impaired the activation of NF- $\kappa B$ and p38 in bone marrow derived macrophages [46]. It appears that tissuespecific SMS targeting could lead to new developments in antiatherosclerotic therapies.

\section{Sphingomyelinase}

Sphingomyelinase (Sphingomyelin phosphodiesterase; SMase; EC3.1.4.12) catalyzes sphingomyelin (SM) breakdown into phosphocholine and ceramide. A few types of SMases have been described so far, depending on their optimal $\mathrm{pH}$ and cation requirements for activity. Among these, important SMases in cardiovascular pathology are (i) secreted and lysosomal acidic zincdependent isoforms, and (ii) membrane magnesium-dependent SMase [47]. Cellular stress activates these SMases with the subsequent generation of ceramide; however, the final effects depend on the SMase type and its cellular locations [48]. The two forms of acidic SMase balance their level on the account of each other, by diverting a common precursor toward Golgi or lysosomes upon receiving specific signals [49]. Most reports point toward a pro-atherogenic role of secretory SMase: it is present in the atherosclerotic lesions and binds specifically to certain subendothelial extracellular matrix constituents, stimulating subendothelial accumulation of atherogenic lipoproteins [50]; increased activity of secretory SMase and specific ceramides in the aorta of apoE-deficient mice during aging were reported [51]; SMase treatment of lipoproteins from apoE-deficient mice enhanced their potential as inducers of macrophage foam cell formation [52]. Additionally, acidic SMase deficient mice on a apoE-/- or LDLR-/atherosclerosis-prone genetic background showed significantly reduced lipid retention and atherosclerotic lesions, despite no alteration in plasma cholesterol or lipoproteins, supporting a causative role of SMase in atherogenesis [53]. Surprisingly, adeno-associated virus-mediated expression of acidic SMase in apoE-deficient mice reduced atherosclerosis [54]. Secretory SMase is released by endothelial cells in vitro upon signaling by inflammatory cytokines. Its level is also increased in LPS treated wild-type mice via IL-1, as demonstrated by abrogation of this increase in IL-1 converting enzyme knockout mice or further enhancement in IL-1-receptor antagonist knockout mice [55]. Macrophages deficient in lysosomal SMase exhibited an impaired cholesterol traffic and efflux [56]. Generation of ceramide via hydrolysis of membrane SM by acidic SMase results in lipid rafts clustering and promotes oxidative stressinduced endothelial dysfunction [57]. Neutral SMase 2 has been also implicated in the evolution of atherosclerosis, mainly in relation to plaque remodeling and fibrous cap degradation [58]. Thus, apoCI and apoCI-enriched HDL activate the neutral SMase-ceramide signaling pathway, leading to apoptosis in human aortic SMCs, an event that may promote plaque rupture in vivo [59]. Other reports of the involvement of neutral SMase in the cardiac pathology are summarized in ref. [60]. A recent study reports that palmitate-induced 
inflammatory response of microvascular endothelial cells to LPS involves neutral SMase [61]. Recently, alkaline sphingomyelinase, which was less related to atherogenic processes, has been implicated as a physiological factor promoting cholesterol absorption by reducing SM levels in the intestinal lumen, as demonstrated in a murine knockout model [62]. Despite the extensive exploration of SMase mechanisms of action, design of specific SMase-type inhibitors is still a challenge and they have not received yet clinical validation [47].

\section{Lipoprotein Metabolism Related Enzymes}

\section{Acyl-coenzyme A: cholesterol acyltransferases (ACAT)}

Acyl-coenzyme A: cholesterol acyltransferase (ACAT; EC 2.3.1.26) catalyzes the conversion of cholesterol to cholesteryl esters (CE) [63], as illustrated in Figure 2. ACAT is part of a family containing also DGAT (diacylglycerol acyltransferase) [64], and MGAT (monoacylglycerol acyltransferase) [65]. The two isoforms of ACAT identified in mammals are differentially expressed: ACAT1 is ubiquitously expressed while ACAT2 is secreted by the liver and small intestine [66]. Increased ACAT1 expression was detected in macrophage-derived foam cells in human atherosclerotic lesions, revealing its contribution to the foam cell formation during atherogenesis [67]. Considering that ACAT1 inhibition prevented the macrophages foam cells formation and thus exerted protective effects against atherosclerosis, several ACAT inhibitors have been synthesized. It was reported that CI-976 ACAT inhibitor was effective in reducing the accumulation of $\mathrm{CE}$ in the atherosclerotic plaques of Yucatan micropig [68]. Likewise, the ACAT inhibitor avasimibe reduced atheroma in rabbits [69] and in apoE3-Leiden mice [70] and F-1394 inhibitor markedly decreased early or advanced atherosclerotic plaques in apoE-deficient mice [71,72]. Despite the promising results noticed in animals, negative results have been obtained in clinical trials. Thus, in A-PLUS (Avasimibe and Progression of Lesions on UltraSound) trial, avasimibe caused a mild increase in LDL-cholesterol and did not positively alter coronary atherosclerosis [73]. In another study, pactimibe treatment of patients with coronary atherosclerosis also failed to reduce the volume of atherosclerotic plaques [74]. These negative results may be due to the lack of selectivity for ACAT1 or ACAT2 of avasimibe and pactimibe. To evaluate whether selective ACAT1 inhibition would lead to beneficial effects against atherosclerosis, ACAT1-/-/apoE-/- and ACAT1-/-/LDLR-/- mice were generated. The results showed that in both strains of double transgenic mice, ACAT1 deficiency had detrimental effects, resulting in dry eye syndrome, extensive xanthomatosis [75], as well as deposition of unesterified cholesterol in skin and brain [76]. Then, the question of whether macrophage-specific ACAT1 inhibition would be effective in treating atherosclerosis was raised. Using LDLR-/- mice lacking ACAT1 in macrophages, Fazio and coworkers noticed that the inability of these cells to esterify cholesterol resulted in a toxic accumulation of free cholesterol and even accelerated atherogenesis [77]. On the other hand, ACAT2-deficient mice were protected against diet-induced hypercholesterolemia and cholesterol gallstone formation due to the lack of CE synthesis in the intestine and consequently a restricted capacity to absorb cholesterol $[78,79]$. Moreover, these mice were also protected from atherosclerosis when they were crossed with apoE-deficient mice [80]. Interestingly, in ACAT2-/-/apoE-/- mice a compensatory increase in LCAT (lecithin cholesterol acyltransferase) activity was noticed, explaining the high levels of HDL-CE. Additionally, mice lacking both ACAT2 and LCAT on LDLR-/- background were highly resistant to atherosclerosis [81].
The complete absence of CE from the plasma of these ACAT2-/-I LCAT-/-/LDLR-/- mice confirmed that there are only two enzymes that possess the ability to synthesize plasma CE, LCAT and ACAT2, but not ACAT1. Another approach for ACAT2-specific inhibition in the liver was the use of antisense oligonucleotides, which resulted in atheroprotection [82].

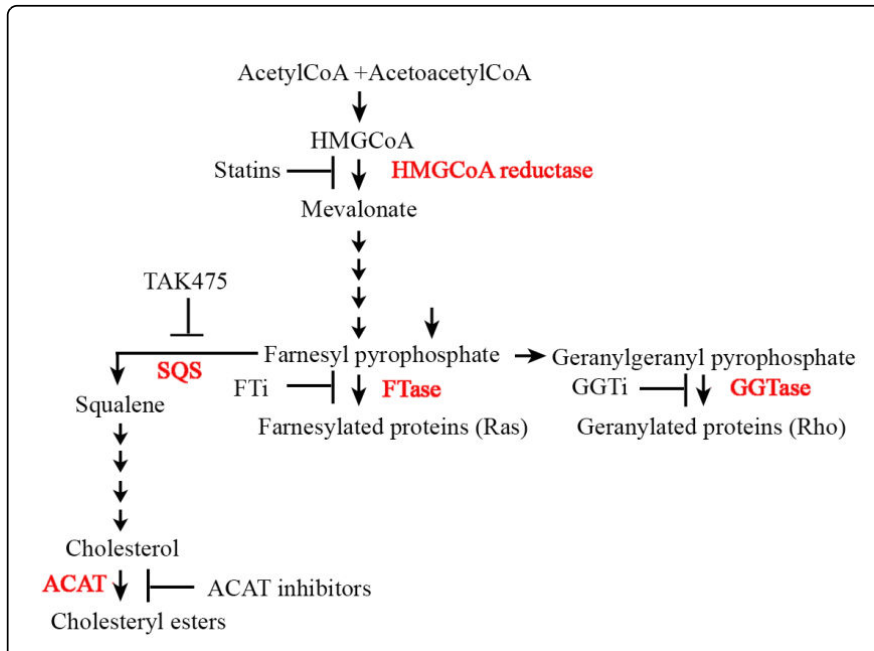

Figure 2: Isoprenoid metabolism with branching pathways leading to cholesterol / cholesteryl esters biosynthesis or protein prenylation. The main enzymes whose inhibition is beneficial in atherosclerosis are highlighted in red. This metabolic pathway links enzymes involved in multiple processes related to cholesterol metabolism, relevant for atherosclerosis.

The results of the studies in mouse models raised the question of whether ACAT2-specific inhibition will protect against atherosclerosis in humans. Hence, the development of selective ACAT2 inhibitors is of utmost importance, but remains a challenge.

\section{Lecithin cholesterol acyltransferases (LCAT)}

Lecithin cholesterol acyltransferase (LCAT; EC 2.3.1.43) is a plasma enzyme playing a key role in the production of plasma $\mathrm{CE}$ and in the formation and maturation of HDL particles. LCAT promotes the reverse cholesterol transport (RCT), by which excess cellular cholesterol is removed from peripheral tissues by HDL and transported to the liver for excretion [83]. Mutations in the LCAT gene can lead to two very rare autosomal recessive disorders: familial LCAT deficiency (FLD), in which the complete lack of LCAT activity affects both $\alpha$-LCAT activity (the esterification on HDL) and $\beta$-LCAT activity (the esterification on LDL) [84], and fish-eye disease (FED), in which only $\alpha$-LCAT activity is reduced [85]. Both disorders are characterized by very low plasma HDL levels and cholesterol deposits in the cornea which cause corneal opacities. Patients with FLD may develop hypertriglyceridemia, as well as renal dysfunctions. Different studies have reported increased [86] or decreased [87] LCAT activity in patients with coronary atherosclerosis confirmed by angiography. The importance of LCAT in the protection against atherosclerosis, as well as the impact of LCAT mutations on HDL-cholesterol levels is highlighted by the study of Hovingh et al. that found enhanced atherosclerosis in heterozygotes for LCAT gene mutations as compared to controls [88]. Increasing the LCAT activity was proposed as a promising anti-atherosclerotic strategy, at least in subjects with 
low LCAT levels. In a 25 year follow-up study, vascular abnormalities and an atherogenic lipid profile were detected in heterozygotes for LCAT deficiency [89]. In contrast, Calabresi et al. reported that low HDL levels in the Italian carriers of LCAT mutations, with total or partial LCAT deficiency, did not result in premature atherosclerosis [90]. An interesting clinical case supporting the paradoxical association between LCAT deficiency, low HDL levels, and absence of subclinical atherosclerosis was recently reported [91]. An explanation for these contradictory findings has been suggested, such as possible involvement of other proteins that could alter the effect of LCAT deficiency on atherosclerosis. As a potential therapy for FLD, Rousset et al. demonstrated the feasibility of the infusion of human recombinant LCAT into LCAT-deficient mice which increased cholesterol efflux and restored the normal lipoprotein phenotype [92]. Despite the numerous studies in animal models and humans focusing on LCAT, well reviewed in ref. [93], its precise role in atherogenesis remains to be clarified. Hence, recombinant LCAT as well as recently developed activators of LCAT may help to answer the question whether increasing LCAT activity is a valuable anti-atherosclerotic strategy.

\section{Lipoprotein-Associated Phospholipases A2}

Lipoprotein-Associated Phospholipase A2 (Lp-PLA2; EC 3.1.1.47) is an enzyme mainly synthesized by the inflammatory cells, and it is transported in the blood mostly on circulating LDL particles and to a lesser extent on HDL and remnant lipoprotein particles (reviewed in ref. [94]). Lp-PLA2 was discovered as platelet-activating factor (PAF) acetyl-hydrolase due to its ability to catalyze the degradation of PAF by hydrolysis of the acetyl group at the sn-2 position, yielding the biologically inactive products, lyso-PAF and acetate [95]. Due to the degradation of proinflammatory PAF and indirect inhibition of platelet activation, Lp-PLA2 was initially considered as an antiinflammatory protein. Thus, it was reported that overexpression of human PAF acetyl-hydrolase (induced by adenovirus-mediated gene transfer) significantly reduced the macrophages recruitment to the atherosclerotic lesion in the aortic root of apoE-/- mice [96]. Likewise, human PAF acetyl-hydrolase gene transfer in apoE-/- mice decreased the oxidized lipoproteins accumulation, inhibited neointima formation and atherosclerosis [97]. However, increasing evidence support a pro-atherogenic role for this enzyme that hydrolyzes oxidized LDL particles generating lyso-phosphatidylcholine and proinflammatory oxidized fatty acids, which can amplify the atherogenic process. Increased expression of Lp-PLA2 by macrophages was detected in human and rabbit atheroma [98]. An association of LpPLA2 expression in vulnerable and ruptured atherosclerotic plaques was also revealed [99]. Moreover, increased Lp-PLA2 activity was positively associated with coronary heart disease [100], suggesting the modulation of the enzyme activity as a potential target in cardiovascular disorders.

Based on the hypothesis that the inhibition of Lp-PLA2 activity may have beneficial effects, a lentiviral-mediated RNAi approach was used to knock-down Lp-PLA2 expression in apoE-deficient mice [101]. The results showed that Lp-PLA2 RNAi reduced inflammation and attenuated the development of atherosclerotic plaques [101]. In diabetic and hypercholesterolemic swine, darapladib, a selective inhibitor of Lp-PLA2, significantly reduced plasma and lesion LpPLA2 activity and inhibited the progression of advanced coronary atherosclerosis [102]. Also, A-002 (Varespladib), an inhibitor of secretory Lp-PLA2, reduced lipid accumulation in the aorta and the development of diet-induced atherosclerosis in guinea pigs, despite any changes in plasma lipids [103]. In spite of the positive effects of Lp-PLA2 inhibitors in mice and pigs, clinical trials that evaluated the darapladib efficiency gave disappointing results. Thus, in the STABILITY study ("Stabilization of Atherosclerotic Plaque by Initiation of Darapladib Therapy"), darapladib failed to diminish the risk of cardiovascular death in patients with stable coronary heart disease [104]. In the SOLID-TIMI 52 study, this pharmacological inhibitor failed to reduce the risk of major coronary events in patients with recent acute coronary syndrome events [105]. In another trial, varespladib treatment increased the risk for myocardial infarction, leading to early termination of the VISTA-16 trial [106].

Recently, the exomes of 6325 participants were sequenced in the "Atherosclerosis Risk in Communities" study in order to find genetic variants of PLA2G7 gene encoding for Lp-PLA2 that reduce its activity and the results of this study showed no association between loss-offunction variants and cardiovascular risk [107].

\section{Proprotein convertase subtilisin/kexin type 9 (PCSK9)}

Proprotein convertase subtilisin/kexin type 9 (PCSK9; EC 3.4.21.111) is a serine protease important for cholesterol homeostasis via hepatic degradation of LDLR [108]. Mutations of PCSK9 are responsible for autosomal dominant hypercholesterolemia, the third hypercholesterolemia-associated genetic locus, after LDLR and ApoB. PCSK9 binds to the epidermal growth factor-like repeat A (EGF-A) domain of LDLR, inducing its degradation, with subsequent decreased metabolism of LDL-cholesterol and hypercholesterolemia [109]. Interestingly enough, the gene was initially identified as being involved in the differentiation of cortical neurons [110]. Since its discovery, a little over a decade, inhibitors of this enzyme have already entered Phase III trials as therapeutic agents for lowering cholesterol level [1]. These inhibitors belong to several classes: monoclonal antibodies (alirocumab, evolocumab), peptide mimetics of the EGFA domain of the LDLR, gene silencers, and small molecules. Safety issues are under research.

\section{Oxidative Stress Related Enzymes}

Reactive oxygen species (ROS) production in limited amounts is required to maintain the physiological redox balance. Oxidative stress appears when ROS levels exceed the detoxifying capability of the cells, and it has deleterious effects on the cellular components, leading to abnormal physiological function and cell death. Oxidative stress exacerbates atherosclerosis. In the vasculature, the major ROSproducing enzymes are represented by NADPH oxidases, cyclooxygenases, lipoxygenases, dysfunctional - "uncoupled" enzymes - endothelial NO synthase (eNOS) and xanthine oxidase, and the mitochondrial respiratory chain [111]. NADPH oxidase, besides its primary function in ROS production, can induce eNOS uncoupling as well as xanthine oxidase activation [112]. Thus, dysfunctional xanthine oxidase and eNOS become ROS-generators only when they are provided with an external source of ROS (e.g. NADPH oxidases), becoming secondary providers of ROS [113]. Besides the ROS producers, there are the enzymatic ROS scavengers, represented by superoxide dismutase (SOD), catalase, glutathione peroxidase (GPx), heme oxygenase, paraoxonase (PON), thioredoxin, glutaredoxin, and peroxiredoxin, etc. These enzymes play important roles in maintaining the normal redox status, and thus may be targeted in atherosclerosis. In this review, we will focus on the main ROS producers (NADPH oxidase and Nitric Oxide Synthase), and on some ROS scavengers (SOD, catalase, GPx, heme oxygenase and PON). Cyclooxygenase and 
lipoxygenase will be discussed in section 6 , since their function is mainly related to the biosynthesis of inflammatory mediators with important role in atherosclerosis development.

\section{NADPH oxidase}

NADPH oxidase (nicotinamide adenine dinucleotide phosphateoxidase, EC 1.6.3.1) is a membrane-bound enzyme complex. There are five isoforms of NADPH oxidase, named from NOX1 to NOX5. NOX is formed by five subunits: a membrane-associated cytochrome b558, containing p22phox and gp91phox, and three cytosolic regulatory subunits, p40phox, p47phox, and p67phox; there are also two different homologs: Nox organizer 1 (Noxo1), a p47phox analog, and Nox activator 1 (Noxa1), a p67phox analog. NOX activation also involves GTP-binding protein, Rac1/2 or Rap 1A. The structure and function of NADPH oxidases are presented in detail by Maneaî [114]. The cells involved in atherosclerosis express NADPH oxidases. Endothelial cells express four NADPH oxidase isoforms, out of which NOX1, 2, and 5 trigger endothelial dysfunction and vascular disease, and NOX4 generates hydrogen peroxide and exerts protective effects on the vessel wall [115]. In macrophages, Nox 1 and Nox 4 are inducible and mediate LDL oxidation [116]. Recently, Nox 5 was revealed to be constitutively expressed in human monocytes and induced in macrophages by IFN $\gamma$ and oxidized LDL, with implications on atherogenesis [117]. SMCs express Nox1, Nox4, and Nox5 and a low Nox2 level and adventitial fibroblasts contain primarily Nox2 and Nox4 [118].

Pharmacological data showed that NOX1- and NOX4 inhibitor (GKT136901) decreased ROS production and atherosclerosis $[119,120]$. Noxal represents a potential pharmacological target for the modulation of ROS production in atherosclerotic arteries [119]. Studies of pharmacological inhibition NOX1/2 using apocynin showed that aortic atherosclerotic lesions of apoE-/-/LDLR-/- double transgenic mice were decreased, especially on descending aorta, but not in the aortic arch [121].

These data corroborated with other studies on two double knockout mice models: apoE-/-/p47phox-/- and apoE-/-/Nox2-/- double knockout mice [122-124] which indicated that the atherosclerotic lesion formation on the aortic sinus was not affected. These data suggest that NOX2 effect on atherogenesis is different in various regions of the vasculature. However, other data from the literature showed that apoE-/-/p47phox-/- mice were protected from atherosclerosis as compared to the apoE-deficient mice, and the atherosclerotic lesions of the whole aorta (including the aortic arch) were diminished $[120,123,125]$.

Contradictory data were also reported for Nox1-/-/apoE-/- mice maintained on a high-fat diet. Sheehan and co-workers reported that these double knockout mice developed fewer and smaller atherosclerotic lesions [126], while another group determined that the lesions were even larger than those found on apoE-/- mice [115].

\section{Nitric Oxide Synthase}

Nitric Oxide Synthase (NOS; EC 1.14.13.39) catalyzes the nitric oxide (NO) production from L-arginine. The endothelial NOS (eNOS) and the neuronal NOS are constitutively expressed and the inducible NOS (iNOS) is biosynthesized in pathological states such as heart failure [127]. At the level of the vasculature, $\mathrm{NO}$ is involved in homeostasis, having vasodilator, antiproliferative and antiplatelet actions, as recently reviewed in ref. [128]. Endothelial NOS is mainly located in endothelial vesicles, named caveolae [129], localization that confers a controlled activation, through the interaction with caveolin-1 [130]. Our previous data showed that eNOS gene polymorphism (eNOSG894T) is a risk factor for cardiovascular diseases and hypertension, but also in other maladies accompanied by endothelial dysfunction such as Fabry's disease [7].

Dysfunctional eNOS ("uncoupled" eNOS) was observed in different pathological states associated with the oxidative stress. In this state, the oxygen reduction is uncoupled from $\mathrm{NO}$ synthesis as recently explained by Heltianu et al. and Takimoto et al. [131,132]. Many experimental trials were done to recouple NOS in cardiovascular diseases including: administration of tetrahydrobiopterin $\mathrm{BH} 4$ (to block upstream ROS production), folic acid (to recycle dihydrobiopterin into $\mathrm{BH} 4$ ) and L-arginine (to supplement the NOS substrate) [132-134].

Experimental studies were performed on animal models using adenovirus-mediated iNOS gene transfer at the site of vascular lesion. The consequent local NO synthesis induced significant proliferation of smooth muscle cells and intimal hyperplasia in rats, processes with important impact on atherosclerosis progression [135].

\section{Superoxide dismutases}

Superoxide dismutases (SOD; EC 1.15.1.1) catalyze the dismutation of the superoxide radical into molecular oxygen and hydrogen peroxide. SOD family includes three isoforms expressed in different cellular compartments: cytosolic $\mathrm{Cu} / \mathrm{Zn}$ SOD1, mitochondrial $\mathrm{Mn}$ SOD2 and $\mathrm{Cu} / \mathrm{Zn}$ extracellular SOD3 [136]. Despite the fact that extracellular SOD genetic deficiency was found to have no influence on atherogenesis in apoE deficient mice [137], SOD local delivery decreased the cuff-induced arterial neointima [138], accelerated the endothelial recovery and inhibited in-stent restenosis in the aorta of Watanabe hyperlipidemic rabbits [139]. Both knockout [140] or overexpression [141] studies showed that mitochondrial SOD protected apoE-deficient mice against atherosclerosis. Dietary supplements up-regulated SOD expression in apoE-deficient mice and attenuated atherosclerosis [142]. Utilization of synthetic SOD mimetics over the native $\mathrm{Cu} / \mathrm{Zn}$ SOD enzyme alleviated endothelial dysfunction in apoE deficient mice. The search for improved cell permeability and stability is expected to lead to the development of more potent drugs [143].

\section{Catalases}

Catalase (CAT, EC 1.11.1.6) is located in peroxisomes where it reduces

$\mathrm{H}_{2} \mathrm{O}_{2}$ to $\mathrm{H}_{2} \mathrm{O}$ and $\mathrm{O}_{2}$. In apoE-/- mice, systemic overexpression of catalase

retarded the development of atherosclerosis, which is further decreased by

combined overexpression of $\mathrm{Cu} / \mathrm{Zn}$-SOD and catalase [141]. In apoEdeficient mice, dietary supplements upregulated CAT expression and reduced atherosclerosis [144,145]. CAT is also powerful in the attenuation of non-dietary atherosclerosis in apoE-deficient mice. Thus, its overexpression in apoE mice exposed to the polycyclic aromatic hydrocarbon benzopyrene, alone or in association with $\mathrm{Cu} / \mathrm{Zn}-\mathrm{SOD}$, led to increased protection as compared with those overexpressing only $\mathrm{Cu} / \mathrm{Zn}-\mathrm{SOD}$ [146].

Although antioxidant enzymes are important therapeutic agents for relieving the vascular oxidative stress, their rapid elimination from the bloodstream compromises their effects. Therefore, various chemical 
and gene delivery methods were envisioned [147,148], to maximize their anti-atherogenic potential.

\section{Glutathione peroxidases}

Glutathione peroxidases (GPx; EC 1.11.1.9) are enzymes with peroxidase activity, playing a protective role against the oxidative damage. Gpx reduce lipid hydroperoxides to the corresponding alcohols and catalyze the conversion of hydrogen peroxide to water. Until present, eight isoforms (GPx-1 to GPx-8) were identified in humans. In the vasculature, GPx deficiency has implications in atherogenesis. The double knockout mouse model (GPx-1-/-/apoE-/-) developed significantly more pronounced atherosclerotic plaques compared to the apoE-/- control [149]. However, GPx-1 deficiency could not induce atherosclerosis in high-fat diet fed C57BL/J6 mice [150]. In humans, decreased GPx-1 activity in red blood cell was found to be related to multivascular atherosclerosis and an augmented cardiovascular risk [151]. Diphenyl diselenide, an organoselenium compound with GPx mimetic abilities was found to inhibit human LDL oxidation in vitro [152] and to reduce the formation of atherosclerotic lesions in hypercholesterolemic LDLR knockout mice [153]. Therefore, it is considered that diphenyl diselenide has antiatherogenic actions by modulating intracellular signaling pathways related to antioxidant and anti-inflammatory responses. GPx-1 role in many diseases and speculations on potential future therapies is reviewed Lubos et al. [154].

\section{Heme oxygenase-1}

Heme oxygenase (HO; EC 1.14.99.3) is an enzyme that catalyzes, in a rate-limiting reaction, the NADPH-dependent degradation of heme, with the production of biliverdin, iron, and carbon monoxide. The beneficial roles exerted by these products of heme catabolism, once believed to be toxic, are nowadays brought to light: $\mathrm{CO}$ is a regulator of vascular tone, bilirubin is a potent anti-oxidant, while iron increases the production of the cytoprotective ferritin [155]. Three isoforms of the enzyme were described so far: HO-1, HO-2 and HO- 3 . Of these isoforms, $\mathrm{HO}-2$ and $\mathrm{HO}-3$ are constitutively expressed, while $\mathrm{HO}-1$ is inducible as a stress response to insults as hypoxia, hyperoxia, endotoxins. Reports of the rare and lethal genetic HO-1 deficiency in humans described severe dysfunctions as intravascular hemolysis and endothelial and renal damage [156] or asplenia and inflammation [157]. HO-1 null mice are characterized by retarded growth, anemia, susceptibility to stress, either oxidative or LPS-induced $[158,159]$. Hypoxia induces apoptosis in cardiomyocytes from heme oxygenase-1 null mice [160] and also compromises the post-ischemic reperfusion response in heterozygous HO-1 mice [161]. HO-1 has become an especially interesting target for atheroprotection since the ablation of heme-binding transcription repressor Bach1 in apoE-deficient mice, which leads to the overexpression of $\mathrm{HO}-1$ in endothelium, macrophages, and vascular SMCs, suppresses atherosclerosis in Bach1/ apoE double knockout mice [162]. This effect was abrogated by Sn protoporphyrin, an inhibitor of $\mathrm{HO}$ activity [163]. HO-1 induction in LDLR-deficient mice by intraperitoneal injections of hemin (H group) or hemin and desferrioxamine (HD group) led to significantly smaller atherosclerotic lesions in the proximal aorta upon feeding a high-fat diet, whereas the group treated with Sn-protoporphyrin presented larger lesions compared with the control group, which received saline only [164]. Another inducer of HO-1, the synthetic phenolic compound butylated hydroxyanisole, was shown to reduce the proliferation of vascular SMCs via p38/MAPK pathway, being thus a therapeutic compound useful in atherosclerosis [165]. Certain less toxic dietary antioxidants also induce HO-1. Besides the pharmacological modulation by inducers of HO-1 gene expression, which sometimes may be affected by certain polymorphisms in the promoter region, alternative strategies may be used for increasing HO-1 activity, such as gene delivery or exogenous delivery of HO-1 products ( $\mathrm{CO}$ and bile pigments). For a comprehensive overview of HO-1 targeting, the reader is directed to Durante [166].

\section{Paraoxonases}

Paraoxonases (PONs; EC 3.1.8.1) are antioxidant enzymes that degrade bioactive oxidized lipids, playing a clear antiatherogenic role. PONs is present in three forms: PON1 and PON3, which are structurally and functionally related to HDL particles in the plasma, and PON2, an intracellular enzyme with a wide cellular distribution [167]. Besides antioxidant properties, PONs have important cardioprotective characteristics, including positive effects on macrophage cholesterol metabolism (PON1), reduction of macrophage triglyceride accumulation (PON2), as well as improvement of bile acids metabolism (PON3). The most studied paraoxonase is $\mathrm{PON} 1$, which has been shown to exert protective effects against lipoprotein oxidation, in particular HDL oxidation [168]. PON1 prevents the accumulation of oxidized LDL and promotes the cholesterol efflux from macrophages. Interestingly, PON1 was found to be able to freely exchange between HDL particles and cell membranes, exerting its antioxidant effects in the new location [169]. A landmark study indicating the atheroprotective role of PON1 is the generation of PON1-deficient mice, which are more susceptible to atherosclerosis than their wild-type littermates [170]. Additionally, the transgenic expression of human PON1 in mice pointed out the ability of this enzyme to retard or reverse atherosclerosis [171,172]. The proposed mechanisms for their atheroprotective role are the following: a reduction in circulating and aortic oxidized-LDL, a decrease in macrophage oxidative stress and foam cell formation [173], a stimulation of reverse cholesterol transport and a normalization of the endothelial function [174]. However, oxidative stress, as well as high levels of cholesterol, triglycerides and glucose can inactivate PON1. In humans, low levels of serum PON1 increase the susceptibility to coronary heart disease, representing a cardiovascular risk factor [175-177]. Immunostaining studies in human aortas indicated a progressive increase of PON1 expression during atherosclerosis development [178]. A natural substrate for PON1 was found to be homocysteine thiolactone, which is associated with atherogenesis related to hyperhomocysteinemia [179]; therefore an important atheroprotective mechanism of PON1 was proposed to take place through metabolizing homocysteine thiolactone and limiting $\mathrm{N}$ homocysteinylation.

The possible relationship between PON genetic polymorphisms and coronary artery disease has just been discussed recently [180]. A metaanalysis of the Q192R, L55M, and T(-107)C polymorphisms in the PON1 gene, as well as of the S311C polymorphism in the PON2 gene found a weak association of coronary heart disease with Q192R polymorphism, but no with the other polymorphisms [181].

Different substrates and assays were proposed for serum PON1 measurement, as a biomarker for diagnosis of diseases related with oxidative stress and inflammation, but there are still problems regarding the variety of substrates and the lack of reference methods $[182,183]$. 


\section{Vascular Remodeling Related Enzymes}

\section{Matrix Metalloproteases}

Matrix metalloproteinases (MMPs) are cell surface or secreted zincdependent endopeptidases that hydrolyze extracellular matrix (ECM) components. Implicated in many biological processes, these proteinases play a central role both in normal tissue functioning (embryogenesis, tissue remodeling, wound healing, angiogenesis, etc.), as well as in various diseases (atheroma, arthritis, cancer, tissue ulceration, etc.). All MMPs have a common structure containing $\mathrm{Zn}^{2+}$ ion at the catalytic active site. Their activity is controlled by specific endogenous inhibitors called tissue inhibitors of metalloproteinases (TIMPs). In humans, MMP family comprises over 20 endopeptidases, which were classified according to Raffetto and Khalil [184] in the following subgroups:

1. MMP-1, MMP-8, MMP-13 and MMP-18 collagenases cleave interstitial collagens I, II and III and other ECM and non-ECM molecules;

2. MMP-2 and MMP-9 gelatinases digest denaturated collagens, as well as native collagen types I, IV, fibronectin and laminin; MMP9 was previously found to be involved in mammalian bone formation by promoting vascular invasion into the growth plate;

3. MMP-3, MMP-10, and MMP-11 digest ECM components;

4. MMP-7 and MMP-26 matrilysins digest cell surface molecules and ECM components;

5. MMP-14, MMP-15, MMP-16, MMP-17, MMP-24, and MMP-25 membrane-type act on ECM molecules and collagen I, II and III;

6. other MMPs, with a role in macrophage migration and digestion of other proteins.

Some of the MMPs family members were identified to be associated with the atherosclerotic lesions both in human and animal models. Moreover, their contribution in the weakening of the vascular wall of the atherosclerotic lesion is well known. Upon MMP activation, matrix degradation leads to plaque rupture causing unstable angina, myocardial infarction and stroke (via destruction of ECM proteins). The stability of the atheromatous plaque depends on the equilibrium between the biosynthesis and the degradation of ECM. MMPs-1, -2 , $-3,-7,-9,-11,-12,-13,-14$, and -16 are upregulated in macrophages found in the human plaques, while in animals, numerous studies showed that MMPs are also upregulated in the atheromatous plaques of cholesterol-fed rabbits and apoE-deficient mice [185,186]. MMP-1, whose inhibition leads to accumulation of collagen in plaques (correlated with resistance to plaque rupture in humans), was found to be linked to human acute coronary diseases. Poor collagen content is found in the fibrous cap of the ruptured atherosclerotic plaque. MMP-9 expression was enhanced in untreated diabetic apoE-/- mice and absent in insulin-treated mice [187]. Moreover, MMP-9 was associated with dysfunctional HDL, which are lipoproteins with antiatherogenic functions [188]. MMP-12 is involved in plaque progression and instability, while MMP-14 expression is enhanced in a distinct subpopulation of foam cell macrophages which have TIMP-3 downregulated [189]. EMMPRIN, an extracellular MMP inducer is expressed in human atherosclerotic plaque and up-regulated in apoE-/- mice, playing a role in the plaque rupture [190,191].

To test whether MMP inhibition has a beneficial effect in atherosclerosis, double-knockout mice of various MMPs on apoE background were generated. Data obtained on apoE-/-/MMP-2-/mice showed that the area of calcified lesions in aortic intima of double-knockout mice was significantly reduced compared to apoE-/mice [192]; in addition, the analysis of aortas from apoE-/-/MMP-2-/mice demonstrated a reduction of osteocalcin and BMP2 expression, which are highly expressed in calcified lesions in apoE-/- mice. Another study demonstrated that adenoviral overexpression of TIMP-1 in apoE-/- mouse model reduced the atherosclerotic lesions [193]. A comprehensive study of Rouis and co-workers [193] analyzed the double knockouts apoE-/-/MMP-3-/-, apoE-/-/MMP-7-/-, apoE-/-/MMP-9-/-, and apoE-/-/MMP-12-/- double versus apoE-/single knockout. The results showed that in apoE-/-/MMP-3-/- and apoE-/-/MMP-9-/- double knockouts, the brachiocephalic artery plaques were larger than in controls. Lesion size was reduced in apoE-/-/MMP-12-/- double knockouts as compared with the controls. Moreover, apoE-/-/MMP-12-/- presented increased SMCs number and fewer macrophages in the plaque suggesting a stable phenotype of the atheroma. ApoE-/-/MMP-7-/- mice displayed a higher content of SMCs in the atherosclerotic plaques than controls, but did not present a change in the plaque stability. MMP-3 and -9 deficient mice indicated the protective role for these MMPs, while MMP-12 determined increased lesion and plaque destabilization.

The development of therapeutic drugs specifically targeting MMPs is relevant for atherogenesis prevention, but also for the stabilization of the mature plaques. Most of the exogenous synthetic inhibitors generally contain a chelating group designed to bind to the catalytic zinc atom in the enzyme active site. RS-130830, a non-selective MMP inhibitor, showed no positive effect on atherogenesis or on the stability of the plaques in apoE-/- mice [194]. However, doxycycline, which inhibits MMPs activity, is capable of decreasing gelatinase activity on atherogenesis in apoE-deficient mice [195]. Inhibition of MMP-3, MMP-12, and MMP-13 in LDLR-/- mice by the broad-spectrum MMP inhibitor CGS 27023A led to a delay in intimal lesions formation, but did not prevent them. A phosphinic peptide (RXP470.1), which inhibits MMP-12, significantly reduced atherosclerotic plaque and stopped the evolution of the lesions in the brachiocephalic arteries in apoE-/- mice [196]. It was reported that MMP13i-A, an inhibitor of MMP-13 collagenase, administrated in apoE-/- mice did not diminish the size of the atherosclerotic plaques, did not affect the accumulation of macrophages or smooth-muscle cells in the lesion site, but substantially increased interstitial collagen content in the intima and fibrous cap of the atheroma [197]. Novel MMPs inhibitors are also being considered and recently reviewed in ref. [198].

Another approach targeting MMPs was based on the use of specific antibodies. EMPIRIN antibody-therapy showed an amelioration in the atheroma of apoE-/- mice, through a mechanism including the reduced migration of monocytes and their accumulation in the plaque [199].

\section{Inflammation Related Enzymes}

Cyclooxygenase and lipoxygenase are involved in the arachidonic acid metabolism, the precursor of the potent lipid mediators, prostaglandins and leukotrienes. These are critical modulators of inflammation, sometimes controversial for atherosclerosis progression [200]. 


\section{Cyclooxygenase}

Cyclooxygenase (COX), named also prostaglandin-endoperoxide synthase (EC 1.14.99.1) is the enzyme responsible for the formation of prostanoids: prostaglandins and thromboxane A2 (TxA2). There are two COX isoforms (constitutive COX-1 and inducible COX-2), of different genetic origins, which are about two-thirds identical and have nearly identical catalytic sites, but exhibit differences which allowed the development of specific inhibitors [201]. Nonsteroidal anti-inflammatory drugs (NSAIDs) inhibit production of prostaglandins by acting on COX-1 and/or 2 COX-2. Nonselective NSAIDs inhibit both isoenzymes (e.g., indomethacin, ibuprofen, naproxen), while selective NSAIDs act on COX-1 (e.g., aspirin) or COX-2 (coxibs, e.g., celecoxib), but their use appeared to be to a certain extent a double-edged sword. While relieving the pain and inflammation, which they were primarily designed for, they also promoted undesired cardiovascular side effects, mainly by compromising the balance between the constitutive vasoconstricting TxA2 produced by platelet COX-1 and the vasodilating endothelial prostacyclin [202]. The results coming from genetic studies are also subjected to many variables, and therefore sometimes contradictory. Disruption of COX-1 gene in apoE-deficient mice led to reduced platelet-vessel wall interactions and decreased lesion size upon high fat feeding. These effects are more intense when both COX-1 alleles are disrupted, as compared with single COX-1 gene deletion [203]. Both COX-1 and COX-2 were involved in early atherogenesis, as shown by selective macrophage depletion in apoE-/- and LDLR-/- mice, respectively [204]. Celecoxib, a selective COX-2 inhibitor, reduced the area of the atherosclerotic plaques in apoE-/- mice for the duration of the treatment. The protective effect was lost when drug administration was interrupted [205]. On the same trend, in high fat-fed LDLR deficient mice, pharmacological inhibition of COX-2 with either selective (rofecoxib) or nonselective (indomethacin) or genetic macrophage-specific COX-2 ablation reduced atherosclerosis [206]. In contrast, COX-2 postnatal deletion on an apoE-deficient background accelerated atherosclerosis in a gender-independent manner [207]. COX-2 specific deletion in macrophages attenuated inflammation, but not atherosclerosis in apoE-deficient mice [208]. In an elegant tandem of knockout studies, FitzGerald and collaborators showed that, when specifically targeted, macrophage COX-2 was pro-atherogenic, as demonstrated by its specific deletion in LDLR-/- mice [209], while endothelial and vascular SMCs COX-2 reduced atherosclerosis in the same murine model [210]. Therefore, a successful therapy would target an anti-inflammatory drug specifically to the macrophage, avoiding other deleterious systemic side effects. A further enhancement could be provided by the use of certain natural COX inhibitors as hyperforin [211] or various flavonoids [212]. Another strategy is the use of dual inhibitors, as in the case of licofelone, a combined lipoxygenase/cyclooxygenase inhibitor which entered Phase III trials [213]. In the end, it is worthwhile to mention that aspirin, an adjuvant for the main atherosclerotic therapy via its anti-thrombotic action by inhibiting platelet COX-1 synthesis of TxA2, is sometimes deprived of its effect in the "aspirin resistance" of multiple etiology [214].

\section{Lipoxygenase}

Lipoxygenases (fatty acid:oxygen oxidoreductase; EC 1.13.11.-) catalyze the dioxygenation of polyunsaturated fatty acids in lipids containing a cis,cis-1,4-pentadienic structure. Among the mammalian arachidonate-related enzymes, 5-lipoxygenase (5-LO), and 12/15- lipoxygenase (12/15-LO) were thoroughly studied in atherosclerosis context [215] in relation to their predominant expression in macrophages. Deficiency of 12/15-LO in bone marrow cells prevented the high-fat induced atherosclerosis in apoE-/- mice to the same extent as complete absence of $12 / 15-\mathrm{LO}$, despite a high level of peroxidized lipids. 12/15-LO deficient macrophages were unable to promote endothelial activation in the presence of native LDL and had decreased capacity to form foam cells when exposed to LDL [216]. Similarly, murine atherosclerotic lesions were significantly reduced when $12 / 15$ LO deficiency was superposed on a LDL-R-/- background [217]. The double 5-LO and 12/15-LO deficiency reduces atherosclerosis in apoEdeficient female mice, while males are rather unaffected by LO deficiency [218], these results being consistent with the genderdependent regulation of leukotrienes synthesis [219]. In the light of the above and other, unmentioned here, studies that point toward a proatherogenic role of lipoxygenases, a degree of uncertainty accompanies other studies pointing toward a cardioprotective role [220]. A partial explanation of the noticed discrepancies was correlated with the genetic complexity of 5-LO genetic locus, since a series of chromosomal congenic subregions were shown to affect the size of aortic lesions independently of 5- LO [221].

\section{Posttranslational Modifications Enzymes Related To Isoprenoid Metabolism}

Prenyltransferases posttranslationally modify proteins by adding an isoprenoid (prenyl) group to the carboxyl terminus of the target protein, such that these proteins become membrane-associated. Most prenylated proteins are involved in cellular signaling where membrane association is essential for their function. Prenyltransferases add a farnesyl or geranylgeranyl group to the cysteine residue of proteins having a C-terminal CAAX box. Farnesyltransferase (FTase) recognizes CAAX boxes where $\mathrm{X}=$ Met, Ser, Gln, Ala, or Cys, whereas geranylgeranyltransferase I (GGTaseI) recognizes CaaX boxes with $\mathrm{X}$ $=$ Leu or Glu [222]. GGTaseI and FTAse I are heterodimers with the same $\alpha$ subunit encoded by the FNTA gene, but with different $\beta$ Zncontaining subunits. Prenylation occurs as a branching pathway of isoprenoid metabolism, while cholesterol biosynthesis is another. Therefore, the two pathways are expected to influence each other. Pathological aspects of prenylations are found in various conditions such as insulin sensitivity, inflammation, cardiac hypertrophy, hepatic lipogenesis [223]. Therefore, development of inhibitors to FTase and GGTase-I would serve therapeutic purposes. The available inhibitors of FTase and GGTase-I can be classified into four categories: (i) small molecules competing with the isoprenoid substrate; (ii) small molecules competing with the protein substrate; (iii) bisubstrate analogs; (iv) Small molecules uncompetitive with any of the substrates [224].

\section{Farnesyltransferase (Protein farnesyltransferase)}

Farnesyltransferase (FTase, protein farnesyltransferase; EC 2.5.1.58) adds the C15- isoprenoid farnesyl to proteins bearing the four amino acid motif CAAX at the carboxyl terminus of a protein, as depicted in Figure 2. FTase targets Ras superfamily of small GTP-binding proteins critical to cell cycle regulation and it was associated with various types of cancer. In mice, FTase knockout is lethal in the embryonic stage, but it is not essential to adult homeostasis. FTase exclusion during tumor progression had a restricted inhibitory effect [225]. The induction of FTase by hyperinsulinemia may partly account for the proliferative and atherogenic effects of insulin [226]. FTase also plays a 
significant role in progeria (Hutchinson-Gilford syndrome), a process of accelerated aging in which patients die prematurely due to atherosclerotic complications. This syndrome is caused by a mutation of the nuclear protein lamin $\mathrm{A}$, which leads to the retention of the farnesyl group on the abnormal lamin A protein, progerin and its accumulation in the nucleus. Progerin accumulation is directly involved in the vascular disease associated with the syndrome [227]. FTase inhibition has proved to be beneficial for the alleviation of the condition $[228,229]$. In the clinical trials of progeric children, FTase inhibitor lonafarnib improved vascular function, bone structure, and audiological status [230]. Manumycin A, a farnesyltransferase inhibitor, prevented atherosclerosis development in apoE-deficient mice fed a Western diet, independently of cholesterol level. Treated animals displayed decreased Ras activity and reduced oxidative stress [231]. FTase inhibitor R115777 hindered protein prenylation in mice with chronic renal failure, with both local and systemic effects: it decreased aortic atherosclerotic lesion area, calcification, vascular nitrotyrosine, total collagen and collagen type I content, restored the normal serum levels of apolipoprotein IV, a globin and fetuin A. In vascular smooth muscle cells, R115777 inhibited type I collagen synthesis and reduced mineral deposition through Ras-Raf pathway [232]. FPT III, a FTase inhibitor, was found to reduce in-stent restenosis by a new, Ras-independent pathway in rabbit models [233]. It was found that TR006, an analog of FTase substrate farnesyl pyrophosphate, which strongly inhibited FTase enzyme activity, blocked the human smooth muscle cells in culture and inhibited growth factor-induced DNA synthesis [234]. Combinations of statins and certain FTIs may exert a concerted action in preventing excessive cell proliferation. Thus, lovastatin and the FTase inhibitor 3allylfarnesol acted synergically to up-regulate and relocate RhoB from the membrane to cytosolic compartments in A10 vascular smooth muscle cells [235]. It is expected that combinations of statins and FTase inhibitors may have therapeutic potential in overproliferation.

\section{Geranylgeranyltransferase-I}

Geranylgeranyltransferase-I (GGTase I, EC 2.5.1.59) is a heterodimer of two subunits: $\alpha$ and $\beta$, encoded by the genes FNTA and PGGT1B, respectively. GGTase I adds the C20-isoprenoid geranylgeranyl group to CAAX-proteins, one of the targets being the RHO proteins (Figure 2). GGTase I inhibitors are being investigated for their therapeutic value in various pathological conditions as inflammation, multiple sclerosis, atherosclerosis. An extensive review of GGTase-1 inhibitors and their classification on structural grounds as natural products, peptide substrate, terpene substrate, etc. is recommended for further information [236]. Cholesterol-fed LDLR-/mice in which GGTaseI was specifically ablated in the macrophages exhibited increased RHO-mediated cholesterol efflux, stimulated macrophage reverse cholesterol transport and reduced aortic atherosclerotic lesions, in spite of a strong inflammatory response [237]. The selective inhibitor GGTI-286 increased the TNFa-mediated overexpression of the endothelial cell adhesion molecule E-selectin, resembling the effect of simvastatin [238]. The same inhibitor GGTI-286 was effective in suppressing phosphatidylcholine hydroperoxide-induced THP-1 cell adhesion to ICAM-1 by interfering with cytoskeletal actin reorganization induced through Rac small GTPase activation [239]. Importantly, inhibition of geranylgeranyltransferase but not inhibition of farnesyltransferase significantly decreased dendritic cells invasion, similarly to atorvastatin. This effect that regulates the interaction between dendritic and endothelial cell may have relevance to inflammation and atherogenesis [240].

\section{Epigenetic Modifications Related Enzymes}

Epigenetic changes, affecting both DNA and histones, emerged recently as therapeutic targets in the field of atherogenesis [241]. Out of the many types of modifications, only some of them will be reviewed below.

\section{Histone deacetylases}

Histone deacetylases (HDAC; EC 3.5.1.98) are enzymes that remove the acetyl groups from $\varepsilon-\mathrm{N}$-acetyl lysine residues of the histones. This modification allows a tighter interaction of the histones with the DNA, and, consequently, it suppresses transcription. Their action is opposed by histone acetyltransferases. Since lysine deacetylation also modulates the activity of other non-histone proteins, HDAC proteins are now considered a subclass of lysine deacetylases (KDAC) [242]. To date, there are 18 mammalian HDACs, which are grouped on structural grounds into four classes. Classes I, II and IV form the Zn-dependent family, while class III (sirtuins) are NAD-dependent enzymes. Other differences relate to the subcellular localization, with most of them nuclear, but others with nuclear-cytosolic shuttling capacity [243]. Histone deacetylase inhibitors were mostly developed to target the tumor evolution [244], three inhibitors: vorinostat (SAHA), Romidepsin and Belinostat being already approved by the US-FDA [245]. However, there is an impressive amount of experimental evidence regarding the involvement of HDACs in cardiovascular pathology, which has been recently reviewed in correlation with the stages of atherosclerosis progression [246]. A different reviewing approach has been used by Lehmann et al., which emphasized the murine cardiac phenotype associated with the ablation of specific HDAC class I (high deacetylase activity) and II (low deacetylase activity), since it appears that each HDAC is endowed with a distinct function in cardiac pathophysiological remodeling [247]. For example, homozygous cardiac-specific HDAC 1 and 2 deletion induced cardiac arrhythmias, dilated cardiomyopathy leading to neonatal lethality [248]. In contrast, transgenic cardiac overexpression of HDAC3 promoted hyperplasia [249]. Therefore, targeting HDAC with panspecific inhibitors may not be a useful approach. HDAC potential in targeting inflammation and other atherogenic events is however increasingly explored, and HDAC pharmacological challenge with inhibitors is claimed to have anti-inflammatory properties and antifibrotic effects in the cerebro- and cardiovascular system [250]. Very recently, it was shown that oral administration of the histone deacetylase inhibitor panobinostat to HIV-infected adults on suppressive antiretroviral therapy in a sub-study of a single-arm, phase I/II clinical trial, led to a significant suppression of HIV-associated inflammation and atherosclerosis. This conclusion was drawn upon evaluation of a panel of cardiovascular risk biomarkers (C-reactive protein, matrix metalloproteinase 9, soluble CD40 ligand, interleukin-6, soluble endothelial selectin) [251]. Cell-specific targeting may increase the chances of therapeutic success through a limitation of the systemic side effects. Thus, endothelial HDAC3 is as an essential prosurvival molecule via Akt activation and conditional Hdac3 knock down in apoE-deficient mice that leads to vessel rupture and advanced atherosclerosis [252]. In contrast, conditional myeloid Hdac3 deficiency promotes collagen deposition in atherosclerotic lesions, stabilizing the plaque and increases macrophage capacity to cope with inflammation and lipid processing [253]. 


\section{DNA methylases}

DNA methyltransferases (DNMT) catalyze the reaction implying the transfer of a methyl group to DNA. DNA methylation serves a wide variety of biological functions. An in-depth review of the mammalian DNMT family covering all the structural and mechanistic details is highly recommended to the reader [254]. DNMT1 (EC 2.1.1.37) is the key member of the family. All known DNMTs use Sadenosyl methionine as the methyl donor. Increased levels of homocysteine, a marker of cardiovascular disease, lead to an elevation of S-adenosylhomocysteine, a potent inhibitor of methyltransferases throughout the whole genome [255], thus creating a molecular connection between homocysteine and atherosclerosis. Arterial branching points affected by the disturbed blood flow are preferred sites for atherosclerotic plaque development. Recent studies reported that blood flow hydrodynamics controls endothelial gene expression via DNMT1-catalyzed DNA methylation, which suppresses various transcription factors like the cAMP-responsive HoxA5 and KLF3. DNMT inhibitor 5-Aza-2'deoxycytidine (5Aza) or DNMT1 siRNA reduces shear stress-induced inflammation. Moreover, 5Aza reduces atherosclerosis in apoE-/- mice [256]. It was shown that homocysteine-induced apoptosis in human umbilical vein endothelial cells proceeds via DNA methylation mediated by DNMT1, and treatment with the DNMT-1 inhibitors epigallocatechin-3-gallate or 5Aza prevented cell death [257]. Both histone- and DNA-methylases were implicated in the LDL-induced repression of KLF2 transcription in endothelial cells. LDL-induced endothelial dysfunction effects were prevented by pharmacological inhibition or gene silencing of DNMT [258]. DNA methylation was also implicated in the reduced autophagy of THP-1 macrophages upon exposure to oxidized LDL (oxLDL) [259]. Additionally, it was shown that oxLDL-induced epigenetic suppression of FOXP3 down-regulated $\mathrm{T}$ regulatory cells, subsequently increasing the risk of acute coronary syndrome [260]. OxLDL raised significantly MMP-2/MMP-9-mediated migration of human aortic SMCs by epigenetic effects mediated by miRNA [261].

\section{Histone methyltransferases}

Histone methyltransferases (histone-lysine N-methyltransferase and histone-arginine N-methyltransferase; EC 2.1.1.43) catalyze the transfer of one to three methyl groups to lysine/arginine residues of histones [262]. The cofactor S-adenosyl methionine is the methyl donor group for both types of histone methyltransferases. Histones methylation is the main chromatin epigenetic modification responsible for gene expression, genomic stability, development, mitosis. The involvement of histone methylation in atherosclerosis was demonstrated in the pro-atherogenic apoE-deficient mice. Histone methylation is affected both by the genetic environment and exogenous factors such as diet, as revealed by the different pre- and post-natal methylation patterns in vascular endothelial and SMCs of apoE-/- mice, as compared with wild-type controls [263]. Reduced H3 histone methylation in peri-renal aortic tissue from all stages of atherosclerotic human patients was recently reported [264]. Accelerated atherosclerosis by high levels of S-adenosyl homocysteine in the plasma was associated with the activation of endoplasmic reticulum stress through modulation of histone methylation [265]. Epigenetic changes involving both histone deacetylases and methyltransferases were involved in the transcriptional control of collagen type I gene in vascular SMCs in response to IFN- $\gamma$, leading to repression of collagen synthesis, with subsequent impact on plaque destabilization [266]. In monocytes, the proinflammatory phenotype induced by oxidized LDL also involves epigenetic changes, revertible by the histone methyltransferase inhibitor methylthioadenosine [267].

\section{Conclusion}

In this review, we have tried to outline the main enzymes connected with the evolution of atherosclerosis, based on their association with a particular event or metabolic pathway (summarized in the supplemental Table 1). Definitely, we were unable to cover, even superficially, in a limited space, all the significant enzymes and, not willingly, some may have been left out. This is a huge domain to describe, and, certainly, an open one, as new enzymes may be discovered, like PCSK9, which evolved in a decade as an important therapeutic target with inhibitors in Phase III trials. With the advent of molecular biology, the last decades acknowledged an increased understanding, at the finest structural level, of the mechanistic basis of action and offered the opportunity for exciting pharmacological approaches in the design of inhibitors. Few final remarks are due at this point. The main achievements in the field still emerged from the direct targeting of cholesterol metabolism, either from the biosynthetic pathway (statins) or the transport processes (PCSK9 inhibitors). An important aspect to be reiterated is that the latter enzyme was initially discovered in connection with neurobiology. It is possible in the future to uncover new functions of enzymes already known. A particular attention needs to be paid to certain genetic diseases, in which atherosclerosis develops indirectly, as in the case of progeria. Also, the sphingolipids are coming toward the front of the stage, as critical players, not simple bystanders. From the cellular types involved, macrophage contribution is crucial, both to lipid processing and to inflammation, as macrophage-specific knockouts of certain genes can revert the effect of a general knockout in a murine atherosclerosis model. From the studies reviewed above we can conclude that there is a long and not always straight way for confirming the in vivo therapeutic potential of an enzyme modulator proved beneficial in vitro. The challenge is enhanced by the multifactorial genesis of atherosclerosis. There seem to be no "magic bullet" to effectively target the disease, but rather a synergy of complementary approaches. As science progresses, novel approaches will emerge. Among these, targeting the main enzymes involved in the atherosclerotic evolution by genetic or pharmacological means remains a source of high expectations. However, neither the genetic nor the pharmacological approach has to be evaluated on its own. A correct appreciation should take both into account and, more importantly, place the experimental data in a significant biological context. From this review and, moreover, from the plethora of data in the literature, one can understand the importance of choosing a proper therapeutic target. To this aim, many aspects should not be neglected, among them: the existence of variants of different or common genetic origin; the spatiotemporal distribution; the existence of natural inhibitors, endogenous and exogenous; the cross-talk between the various metabolic pathways, with their regulation; the lesional stage at which a drug is expected to act. Extrapolation from in vitro and in vivo models to clinical trials has proved disappointing many times, and in certain cases, never too rare, dangerous. The sooner pitfalls and misinterpretations will be detected, the better both for the benefit of people and to reduce the economic burden associated with death endclinical trials. 
Citation: Fuior EV, Trusca VG, Roman C, Gafencu AV (2015) Enzymatic Targets in Atherosclerosis. J Mol Genet Med 9: 176. doi:

\begin{tabular}{|c|c|c|c|}
\hline & Enzyme & $\begin{array}{l}\text { Athero- } \\
\text { protective(+)/ } \\
\text { atherogenic } \\
(-)\end{array}$ & Representative experimental data (with corresponding references) \\
\hline \multirow{2}{*}{$\begin{array}{l}\text { Cholesterol } \\
\text { biosynthesis related } \\
\text { enzymes }\end{array}$} & HMG-CoA reductases & $(-)$ & Inhibited by statins, which reduce LDL-cholesterol $[5,6]$ \\
\hline & Squalene synthase & $(-)$ & Inhibited by TAK-475, which reduces LDL-cholesterol [20] \\
\hline \multirow[t]{3}{*}{$\begin{array}{l}\text { Sphingolipid } \\
\text { metabolism related } \\
\text { enzymes }\end{array}$} & $\begin{array}{l}\text { Serine palmitoyl } \\
\text { transferase }\end{array}$ & $(-)$ & Inhibition by myriocin led to increased HDL, decreased VLDL and LDL in apoE-/- mice [26] \\
\hline & $\begin{array}{l}\text { Sphingomyelin } \\
\text { Synthase }\end{array}$ & $(-)$ & $\begin{array}{l}\text { Knockout of SMS1 [43] or SMS2 [39] decreased pro-atherogenic NF-KB activation and reduced } \\
\text { atherogenic lipoproteins. }\end{array}$ \\
\hline & Sphingomyelinase & $(-)$ & $\begin{array}{l}\text { Acidic SMase knockout reduced lipid retention and atherosclerotic lesions [53]; neutral SMase } \\
\text { knockout reduced palmitate-induced inflammation [61]; alkaline SMase knockout blocked intestinal } \\
\text { cholesterol absorption [62] }\end{array}$ \\
\hline \multirow{4}{*}{$\begin{array}{l}\text { Lipoprotein } \\
\text { metabolism related } \\
\text { enzymes }\end{array}$} & ACAT1, ACAT2 & $(-)$ & $\begin{array}{l}\text { ACAT2 knockout reduced cholesterol absorption, hypercholesterolemia and gallstones formation [78, } \\
\text { 79]; ACAT2--//apoE-/- mice were highly resistant to atherosclerosis [80] }\end{array}$ \\
\hline & LCAT & $(+)$ & $\begin{array}{l}\text { Increased LCAT expression by infusion increased cholesterol efflux and normalized lipoproteins in } \\
\text { LCAT-I- mice [92] }\end{array}$ \\
\hline & Lp-PLA2 & $(-)$ & $\begin{array}{l}\text { Inhibition by RNAi }[101] \text { and selective inhibitors }[102,103] \text { reduced lipid accumulation and progression } \\
\text { of coronary atherosclerosis in various atherogenic experimental models }\end{array}$ \\
\hline & PCSK9 & $(-)$ & Inhibition by alirocumarib reduced LDL levels [1] \\
\hline \multirow[t]{7}{*}{$\begin{array}{l}\text { Oxidative stress } \\
\text { related enzymes }\end{array}$} & NADPH oxidase & $(-)$ & $\begin{array}{l}\text { NOX1/4 inhibitor GKT136901 reduced ROS [119,120]; NOX1/2 inhibitor apocynin reduced aortic } \\
\text { lesions in apoE-/- LDLR-/- mice [121] }\end{array}$ \\
\hline & Nitric Oxide Synthase & $(+)$ & $\begin{array}{l}\text { Adenovirus-mediated iNOS gene transfer studies showed that local NO synthesis induced significant } \\
\text { proliferation of SMCs and intimal hyperplasia in rats [135] }\end{array}$ \\
\hline & $\begin{array}{l}\text { Superoxide } \\
\text { dismutases }\end{array}$ & $(+)$ & $\begin{array}{l}\text { SOD local delivery decreased the cuff-induced arterial neointima [138], accelerated endothelial } \\
\text { recovery and inhibited in-stent restenosis in the aorta of Watanabe rabbits [139]; mitochondrial SOD } \\
\text { protected apoE-/- mice against atherosclerosis }[140,141]\end{array}$ \\
\hline & Catalases & $(+)$ & $\begin{array}{l}\text { Overexpression retarded atherosclerosis development in apoE-/- mice [141]; dietary supplements } \\
\text { upregulated CAT expression in apoE-/- mice and reduced atherosclerosis [144,145]; CAT attenuated } \\
\text { non-dietary atherosclerosis in apoE-/- mice [146] }\end{array}$ \\
\hline & $\begin{array}{l}\text { Glutathione } \\
\text { peroxidases }\end{array}$ & $(+)$ & Mimetic diphenyl diselenide reduced atherosclerotic lesions in LDLR-/- mice [153] \\
\hline & Heme oxygenase-1 & $(+)$ & Inducers hemin \pm desferrioxamine reduced atherosclerotic lesions in LDLR-/- mice [164] \\
\hline & Paraoxonases & $(+)$ & $\begin{array}{l}\text { Reduced protein } \mathrm{N} \text {-homocysteinylation, prevented accumulation of oxLDL, promoted cholesterol } \\
\text { efflux from macrophages [173], improved endothelial function [174] }\end{array}$ \\
\hline $\begin{array}{l}\text { Vascular } \\
\text { remodeling related } \\
\text { enzymes }\end{array}$ & $\begin{array}{l}\text { Matrix } \\
\text { Metalloproteases }\end{array}$ & $(-) /(+)$ & $\begin{array}{l}\text { Area of aortic calcified lesions was reduced in apoE-/-/MMP2-/- mice compared to apoE-/- mice } \\
\text { ([192]); apoE-///MMP-3-/- and apoE-///MMP-9-/- mice had larger brachiocephalic artery plaques [193], } \\
\text { while lesion size was reduced in apoE-///MMP-12-/- mice [193] }\end{array}$ \\
\hline \multirow[t]{2}{*}{$\begin{array}{l}\text { Inflammation } \\
\text { related enzymes }\end{array}$} & Cyclooxygenase & $(-)$ & $\begin{array}{l}\text { COX-1 knockout in apoE-/- mice reduced platelet-vascular wall interactions and decreased lesions } \\
\text { [203] }\end{array}$ \\
\hline & Lipoxygenase & $(-)$ & $\begin{array}{l}12 / 15 \text { LO knockout in macrophages impaired oxLDL-induced foam cell formation and endothelial } \\
\text { activation [216] }\end{array}$ \\
\hline \multirow{2}{*}{$\begin{array}{l}\text { Posttranslational } \\
\text { modifications } \\
\text { enzymes related to } \\
\text { isoprenoid } \\
\text { metabolism }\end{array}$} & Farnesyltransferase & $(-)$ & $\begin{array}{l}\text { Inhibition by manumycin A reduced Ras activity and oxidative stress [231]; FPTIII reduced in-stent } \\
\text { restenosis in a Ras-independent pathway in rabbit model [233]; 3-allyl farnesol and lovastatin } \\
\text { promoted relocation of RhoB to the cytosolic compartment in vascular SMC [235] }\end{array}$ \\
\hline & $\begin{array}{l}\text { Geranylgeranyl } \\
\text { transferase-I }\end{array}$ & $(-)$ & GGTI-286 inhibitor blocked interaction between monocytes and endothelium [239] \\
\hline $\begin{array}{l}\text { Epigenetic } \\
\text { modifications } \\
\text { related enzymes }\end{array}$ & Histone deacetylases & $(-)$ & Panobinostat inhibitor reduced HIV-associated inflammation and atherosclerosis [251] \\
\hline
\end{tabular}




\begin{tabular}{|l|l|l|l|}
\hline & DNA methylases & $(-)$ & $\begin{array}{l}\text { 5Aza, a DNMT inhibitor, reduced shear-stress induced inflammation and atherosclerosis in apoE-/- } \\
\text { mice [256] }\end{array}$ \\
\cline { 2 - 4 } & $\begin{array}{l}\text { Histone } \\
\text { methyltransferases }\end{array}$ & $(-)$ & $\begin{array}{l}\text { Homocysteine-induced ER-stress can be inhibited by the histone methylase inhibitor } \\
\text { methylthioadenosine [267] }\end{array}$ \\
\hline
\end{tabular}

Table 1: Enzymes used as therapeutic targets in atherosclerosis.

\section{Acknowledgements}

This work was supported by a grant of the Romanian National Authority for Scientific Research, National Research Council Executive Agency for Higher Education, Research, Development and Innovation Funding (CNCS - UEFISCDI), PN-II-IDPCE-2011-3-0591 (grant awarded to AG), and by the Romanian Academy. Corina Roman and Violeta Trusca acknowledge the support of the strategic grant POSDRU/159/1.5/S/133391-financed by the European Social Found within the Sectorial Operational Program Human Resources Development 2007 - 2013.

\section{References}

1. Ladeiras-Lopes R, Agewall S, Tawakol A3, Staels B4, Stein E5, et al. (2015) Atherosclerosis: Recent trials, new targets and future directions. Int J Cardiol 192: 72-81.

2. Catapano AL, Farnier M, Foody JM, Toth PP, Tomassini JE, et al. (2014) Combination therapy in dyslipidemia: where are we now? Atherosclerosis 237: 319-335.

3. Brown MS, Goldstein JL (1980) Multivalent feedback regulation of HMG CoA reductase, a control mechanism coordinating isoprenoid synthesis and cell growth. J Lipid Res 21: 505-517.

4. Miida T, Hirayama S, Nakamura Y (2004) Cholesterol-independent effects of statins and new therapeutic targets: ischemic stroke and dementia. J Atheroscler Thromb 11: 253-264.

5. Liao JK, Laufs U (2005) Pleiotropic effects of statins. Annu Rev Pharmacol Toxicol 45: 89-118.

6. Mihos CG, Salas MJ, Santana O (2010) The pleiotropic effects of the hydroxy-methyl-glutaryl-CoA reductase inhibitors in cardiovascular disease: a comprehensive review. Cardiol Rev 18: 298-304.

7. Jones PH1 (2003) Comparing HMG-CoA reductase inhibitors. Clin Cardiol 26: I15-20.

8. Baigent C, Keech A, Kearney PM, Blackwell L, Buck G, et al. (2005) Efficacy and safety of cholesterol-lowering treatment: prospective metaanalysis of data from 90,056 participants in 14 randomised trials of statins. Lancet 366: 1267-1278.

9. Olsson AG1, Schwartz GG, Szarek M, Sasiela WJ, Ezekowitz MD, et al. (2005) High-density lipoprotein, but not low-density lipoprotein cholesterol levels influence short-term prognosis after acute coronary syndrome: results from the MIRACL trial. Eur Heart J 26: 890-6.

10. Rosenson RS (2004) Current overview of statin-induced myopathy. Am J Med 116: 408-416.

11. Guthrie RM, Martin DR (2007) The safety of rosuvastatin: effects on renal and hepatic function. Expert Opin Drug Saf 6: 573-581.

12. Preiss D, Seshasai SR, Welsh P, Murphy SA, Ho JE, et al. (2011) Risk of incident diabetes with intensive-dose compared with moderate-dose statin therapy: a meta-analysis. JAMA 305: 2556-2564.

13. Rojas-Fernandez C, Hudani Z, Bittner V3 (2015) Statins and cognitive side effects: what cardiologists need to know. Cardiol Clin 33: 245-256.

14. Mihos CG, Pineda AM, Santana O2 (2014) Cardiovascular effects of statins, beyond lipid-lowering properties. Pharmacol Res 88: 12-19.

15. Noyes AM, Thompson PD2 (2014) A systematic review of the time course of atherosclerotic plaque regression. Atherosclerosis 234: 75-84.
16. Stamellos KD, Shackelford JE, Shechter I, Jiang G, Conrad D, et al. (1993) Subcellular localization of squalene synthase in rat hepatic cells. Biochemical and immunochemical evidence. J Biol Chem 268: 12825-12836.

17. Tozawa R, Ishibashi S, Osuga J, Yagyu H, Oka T, et al. (1999) Embryonic lethality and defective neural tube closure in mice lacking squalene synthase. J Biol Chem 274: 30843-30848.

18. Okazaki H, Tazoe F, Okazaki S, Isoo N, Tsukamoto K, et al. (2006) Increased cholesterol biosynthesis and hypercholesterolemia in mice overexpressing squalene synthase in the liver. J Lipid Res 47: 1950-1958.

19. Kourounakis AP, Katselou MG, Matralis AN, Ladopoulou EM, Bavavea E (2011) Squalene synthase inhibitors: An update on the search for new antihyperlipidemic and antiatherosclerotic agents. Curr Med Chem 18: 4418-4439.

20. Shiomi M, Yamada S, Amano Y, Nishimoto T, Ito T (2008) Lapaquistat acetate, a squalene synthase inhibitor, changes macrophage/lipid-rich coronary plaques of hypercholesterolaemic rabbits into fibrous lesions. Br J Pharmacol 154: 949-957.

21. Stein EA, Bays H, O'Brien D, Pedicano J, Piper E, et al. (2011) Lapaquistat acetate: development of a squalene synthase inhibitor for the treatment of hypercholesterolemia. Circulation 123: 1974-1985.

22. Hla T, Dannenberg AJ (2012) Sphingolipid signaling in metabolic disorders. Cell Metab 16: 420-434.

23. Lemaire-Ewing S, Lagrost L, Néel D (2012) Lipid rafts: a signalling platform linking lipoprotein metabolism to atherogenesis. Atherosclerosis 221: 303-310.

24. Jiang XC, Paultre F, Pearson TA, Reed RG, Francis CK, et al. (2000) Plasma sphingomyelin level as a risk factor for coronary artery disease. Arterioscler Thromb Vasc Biol 20: 2614-2618.

25. Slotte JP1 (2013) Biological functions of sphingomyelins. Prog Lipid Res 52: 424-437.

26. Park TS, Panek RL, Rekhter MD, Mueller SB, Rosebury WS, et al. (2006) Modulation of lipoprotein metabolism by inhibition of sphingomyelin synthesis in ApoE knockout mice. Atherosclerosis 189: 264-272.

27. Yasuda S, Nishijima M, Hanada K (2003) Localization, topology, and function of the LCB1 subunit of serine palmitoyltransferase in mammalian cells. J Biol Chem 278: 4176-4183.

28. Hornemann T, Richard S, Rütti MF, Wei Y, von Eckardstein A (2006) Cloning and initial characterization of a new subunit for mammalian serine-palmitoyltransferase. J Biol Chem 281: 37275-37281.

29. Hornemann T, Wei Y, von Eckardstein A (2007) Is the mammalian serine palmitoyltransferase a high-molecular-mass complex? Biochem J 405: 157-164.

30. Hojjati MR, Li Z, Jiang XC (2005) Serine palmitoyl-CoA transferase (SPT) deficiency and sphingolipid levels in mice. Biochim Biophys Acta 1737: 44-51.

31. Miyake Y, Kozutsumi Y, Nakamura S, Fujita T, Kawasaki T (1995) Serine palmitoyltransferase is the primary target of a sphingosine-like immunosuppressant, ISP-1/myriocin. Biochem Biophys Res Commun 211: 396-403.

32. Hojjati MR, Li Z, Zhou H, Tang S, Huan C, et al. (2005) Effect of myriocin on plasma sphingolipid metabolism and atherosclerosis in apoE-deficient mice. J Biol Chem 280: 10284-10289.

33. Glaros EN, Kim WS, Quinn CM, Jessup W, Rye KA, et al. (2008) Myriocin slows the progression of established atherosclerotic lesions in apolipoprotein E gene knockout mice. J Lipid Res 49: 324-331. 
34. Glaros EN, Kim WS, Rye KA, Shayman JA, Garner B (2008) Reduction of plasma glycosphingolipid levels has no impact on atherosclerosis in apolipoprotein E-null mice. J Lipid Res 49: 1677-1681.

35. Geekiyanage H, Chan C (2011) MicroRNA-137/181c regulates serine palmitoyltransferase and in turn amyloid $\hat{\mathrm{I}}^{2}$, novel targets in sporadic Alzheimer's disease. J Neurosci 31: 14820-14830.

36. Huitema K, van den Dikkenberg J, Brouwers JF, Holthuis JC (2004) Identification of a family of animal sphingomyelin synthases. EMBO J 23: 33-44.

37. Zhao YR, Dong JB, Li Y, Wu MP (2012) Sphingomyelin synthase 2 overexpression induces expression of aortic inflammatory biomarkers and decreases circulating EPCs in ApoE KO mice. Life Sci 90: 867-873.

38. Liu J, Zhang H, Li Z, Hailemariam TK, Chakraborty M, et al. (2009) Sphingomyelin synthase 2 is one of the determinants for plasma and liver sphingomyelin levels in mice. Arterioscler Thromb Vasc Biol 29: 850-856.

39. Hailemariam TK, Huan C, Liu J, Li Z, Roman C, et al. (2008) Sphingomyelin synthase 2 deficiency attenuates NFkappaB activation. Arterioscler Thromb Vasc Biol 28: 1519-1526.

40. Fan Y, Shi F, Liu J, Dong J, Bui HH, et al. (2010) Selective reduction in the sphingomyelin content of atherogenic lipoproteins inhibits their retention in murine aortas and the subsequent development of atherosclerosis. Arterioscler Thromb Vasc Biol 30: 2114-2120.

41. Liu J, Huan C, Chakraborty M, Zhang H, Lu D, et al. (2009) Macrophage sphingomyelin synthase 2 deficiency decreases atherosclerosis in mice. Circ Res 105: 295-303.

42. Yamaoka S, Miyaji M, Kitano T, Umehara H, Okazaki T (2004) Expression cloning of a human cDNA restoring sphingomyelin synthesis and cell growth in sphingomyelin synthase-defective lymphoid cells. J Biol Chem 279: 18688-18693.

43. Li Z, Fan Y, Liu J, Li Y, Huan C, et al. (2012) Impact of sphingomyelin synthase 1 deficiency on sphingolipid metabolism and atherosclerosis in mice. Arterioscler Thromb Vasc Biol 32: 1577-1584.

44. Yano M, Yamamoto T, Nishimura N, Gotoh T, Watanabe K, et al. (2013) Increased oxidative stress impairs adipose tissue function in sphingomyelin synthase 1 null mice. PLoS One 8: e61380.

45. Deng X, Lin F, Zhang Y, Li Y, Zhou L, et al. (2014) Identification of small molecule sphingomyelin synthase inhibitors. Eur J Med Chem 73: 1-7.

46. Lou B, Dong J, Li Y, Ding T, Bi T, et al. (2014) Pharmacologic inhibition of sphingomyelin synthase (SMS) activity reduces apolipoprotein-B secretion from hepatocytes and attenuates endotoxin-mediated macrophage inflammation. PLoS One 9: e102641.

47. Pavoine C, Pecker F (2009) Sphingomyelinases: their regulation and roles in cardiovascular pathophysiology. Cardiovasc Res 82: 175-183.

48. Jenkins RW, Canals D, Hannun YA (2009) Roles and regulation of secretory and lysosomal acid sphingomyelinase. Cell Signal 21: 836-846.

49. Marathe S, Schissel SL, Yellin MJ, Beatini N, Mintzer R, et al. (1998) Human vascular endothelial cells are a rich and regulatable source of secretory sphingomyelinase. Implications for early atherogenesis and ceramide-mediated cell signaling. J Biol Chem 273: 4081-4088.

50. Marathe S, Kuriakose G, Williams KJ, Tabas I (1999) Sphingomyelinase, an enzyme implicated in atherogenesis, is present in atherosclerotic lesions and binds to specific components of the subendothelial extracellular matrix. Arteriosclerosis, thrombosis, and vascular biology 19: 2648-2658.

51. Kobayashi K, Nagata E, Sasaki K, Harada-Shiba M, Kojo S, et al. (2013) Increase in secretory sphingomyelinase activity and specific ceramides in the aorta of apolipoprotein E knockout mice during aging. Biological \& pharmaceutical bulletin 36: 1192-1196.

52. Marathe S, Choi Y, Leventhal AR, Tabas I (2000) Sphingomyelinase converts lipoproteins from apolipoprotein E knockout mice into potent inducers of macrophage foam cell formation. Arterioscler Thromb Vasc Biol 20: 2607-2613.

53. Devlin CM, Leventhal AR, Kuriakose G, Schuchman EH, Williams KJ, et al. (2008) Acid sphingomyelinase promotes lipoprotein retention within early atheromata and accelerates lesion progression. Arterioscler Thromb Vasc Biol 28: 1723-1730.

54. Leger AJ, Mosquea LM, Li L, Chuang W, Pacheco J, et al. (2011) Adenoassociated virus-mediated expression of acid sphingomyelinase decreases atherosclerotic lesion formation in apolipoprotein $\mathrm{E}(-/-)$ mice. J Gene Med 13: 324-332.

55. Wong ML, Xie B, Beatini N, Phu P, Marathe S, et al. (2000) Acute systemic inflammation up-regulates secretory sphingomyelinase in vivo: a possible link between inflammatory cytokines and atherogenesis. Proc Natl Acad Sci U S A 97: 8681-8686.

56. Leventhal AR, Chen W, Tall AR, Tabas I (2001) Acid sphingomyelinasedeficient macrophages have defective cholesterol trafficking and efflux. J Biol Chem 276: 44976-44983.

57. Li X, Han WQ, Boini KM, Xia M, Zhang Y, et al. (2013) TRAIL death receptor 4 signaling via lysosome fusion and membrane raft clustering in coronary arterial endothelial cells: evidence from ASM knockout mice. J Mol Med (Berl) 91: 25-36.

58. Horres CR, Hannun YA (2012) The roles of neutral sphingomyelinases in neurological pathologies. Neurochem Res 37: 1137-1149.

59. Kolmakova A, Kwiterovich P, Virgil D, Alaupovic P, Knight-Gibson C, et al. (2004) Apolipoprotein C-I induces apoptosis in human aortic smooth muscle cells via recruiting neutral sphingomyelinase. Arterioscler Thromb Vasc Biol 24: 264-269.

60. Chatterjee S1 (1999) Neutral sphingomyelinase: past, present and future. Chem Phys Lipids 102: 79-96.

61. Lu Z, Li Y, Jin J, Zhang X, Hannun YA3, et al. (2015) GPR40/FFA1 and neutral sphingomyelinase are involved in palmitate-boosted inflammatory response of microvascular endothelial cells to LPS. Atherosclerosis 240: 163-173.

62. Zhang P, Chen Y, Cheng Y, Hertervig E, Ohlsson L, et al. (2014) Alkaline sphingomyelinase (NPP7) promotes cholesterol absorption by affecting sphingomyelin levels in the gut: A study with NPP7 knockout mice. American journal of physiology. Gastrointestinal and liver physiology 306: G903-908.

63. Buhman KF, Accad M, Farese RV (2000) Mammalian acylCoA:cholesterol acyltransferases. Biochim Biophys Acta 1529: 142-154.

64. Cases S, Smith SJ, Zheng YW, Myers HM, Lear SR, et al. (1998) Identification of a gene encoding an acyl CoA:diacylglycerol acyltransferase, a key enzyme in triacylglycerol synthesis. Proc Natl Acad Sci U S A 95: 13018-13023.

65. Cao J, Lockwood J, Burn P, Shi Y (2003) Cloning and functional characterization of a mouse intestinal acyl-CoA:monoacylglycerol acyltransferase, MGAT2. J Biol Chem 278: 13860-13866.

66. Lee RG, Willingham MC, Davis MA, Skinner KA, Rudel LL (2000) Differential expression of ACAT1 and ACAT2 among cells within liver, intestine, kidney, and adrenal of nonhuman primates. J Lipid Res 41: 1991-2001.

67. Miyazaki A, Sakashita N, Lee O, Takahashi K, Horiuchi S, et al. (1998) Expression of ACAT-1 protein in human atherosclerotic lesions and cultured human monocytes-macrophages. Arterioscler Thromb Vasc Biol 18: 1568-1574.

68. Bocan TM, Mueller SB, Uhlendorf PD, Brown EQ, Mazur MJ, et al. (1993) Inhibition of acyl-CoA cholesterol O-acyltransferase reduces the cholesteryl ester enrichment of atherosclerotic lesions in the Yucatan micropig. Atherosclerosis 99: 175-186.

69. Bocan TM, Krause BR, Rosebury WS, Mueller SB, Lu X, et al. (2000) The ACAT inhibitor avasimibe reduces macrophages and matrix metalloproteinase expression in atherosclerotic lesions of hypercholesterolemic rabbits. Arterioscler Thromb Vasc Biol 20: 70-79.

70. Delsing DJ, Offerman EH, van Duyvenvoorde W, van Der Boom H, de Wit EC, et al. (2001) Acyl-CoA:cholesterol acyltransferase inhibitor avasimibe reduces atherosclerosis in addition to its cholesterol-lowering effect in ApoE³-Leiden mice. Circulation 103: 1778-1786.

71. Kusunoki J, Hansoty DK, Aragane K, Fallon JT, Badimon JJ, et al. (2001) Acyl-CoA:cholesterol acyltransferase inhibition reduces atherosclerosis in apolipoprotein E-deficient mice. Circulation 103: 2604-2609. 
72. Rong JX, Blachford C, Feig JE, Bander I, Mayne J, et al. (2013) ACAT inhibition reduces the progression of preexisting, advanced atherosclerotic mouse lesions without plaque or systemic toxicity. Arterioscler Thromb Vasc Biol 33: 4-12.

73. Tardif JC, Grégoire J, L'Allier PL, Anderson TJ, Bertrand O, et al. (2004) Effects of the acyl coenzyme A:cholesterol acyltransferase inhibitor avasimibe on human atherosclerotic lesions. Circulation 110:3372-3377.

74. Nissen SE, Tuzcu EM, Brewer HB, Sipahi I, Nicholls SJ, et al. (2006) Effect of ACAT inhibition on the progression of coronary atherosclerosis. N Engl J Med 354: 1253-1263.

75. Yagyu H, Kitamine T, Osuga J, Tozawa R, Chen Z, et al. (2000) Absence of ACAT-1 attenuates atherosclerosis but causes dry eye and cutaneous xanthomatosis in mice with congenital hyperlipidemia. J Biol Chem 275: 21324-21330

76. Accad M, Smith SJ, Newland DL, Sanan DA, King LE, Jr., et al. (2000) Massive xanthomatosis and altered composition of atherosclerotic lesions in hyperlipidemic mice lacking acyl CoA:cholesterol acyltransferase 1. The Journal of clinical investigation 105: 711-719.

77. Fazio S, Major AS, Swift LL, Gleaves LA, Accad M, et al. (2001) Increased atherosclerosis in LDL receptor-null mice lacking ACAT1 in macrophages. J Clin Invest 107: 163-171.

78. Buhman KK, Accad M, Novak S, Choi RS, Wong JS, et al. (2000) Resistance to diet-induced hypercholesterolemia and gallstone formation in ACAT2-deficient mice. Nat Med 6: 1341-1347.

79. Repa JJ, Buhman KK, Farese RV Jr, Dietschy JM, Turley SD (2004) ACAT2 deficiency limits cholesterol absorption in the cholesterol-fed mouse: impact on hepatic cholesterol homeostasis. Hepatology 40: 1088-1097.

80. Willner EL, Tow B, Buhman KK, Wilson M, Sanan DA, et al. (2003) Deficiency of acyl CoA:cholesterol acyltransferase 2 prevents atherosclerosis in apolipoprotein E-deficient mice. Proc Natl Acad Sci U S A 100: 1262-1267.

81. Lee RG, Kelley KL, Sawyer JK, Farese RV, Jr., Parks JS, et al. (2004) Plasma cholesteryl esters provided by lecithin:cholesterol acyltransferase and acyl-coenzyme a:cholesterol acyltransferase 2 have opposite atherosclerotic potential. Circulation research 95: 998-1004.

82. Bell TA, 3rd, Brown JM, Graham MJ, Lemonidis KM, Crooke RM, et al. (2006) Liver-specific inhibition of acyl-coenzyme a:cholesterol acyltransferase 2 with antisense oligonucleotides limits atherosclerosis development in apolipoprotein B100-only low-density lipoprotein receptor-/- mice. Arteriosclerosis, thrombosis, and vascular biology 26: 1814-1820.

83. Glomset JA (1968) The plasma lecithins:cholesterol acyltransferase reaction. J Lipid Res 9: 155-167.

84. Gjone E, Norum KR (1968) Familial serum cholesterol ester deficiency. Clinical study of a patient with a new syndrome. Acta Med Scand 183: 107-112.

85. Carlson LA, Holmquist L (1985) Paradoxical esterification of plasma cholesterol in fish eye disease. Acta medica Scandinavica 217: 491-499.

86. Wells IC, Peitzmeier G, Vincent JK (1986) Lecithin: cholesterol acyltransferase and lysolecithin in coronary atherosclerosis. Exp Mol Pathol 45: 303-310.

87. Solajic-Bozicevic N, Stavljenic-Rukavina A, Sesto M (1994) Lecithincholesterol acryltransferase activity in patients with coronary artery disease examined by coronary angiography. Clin Investig 72: 951-956.

88. Hovingh GK, Hutten BA, Holleboom AG, Petersen W, Rol P, et al. (2005) Compromised LCAT function is associated with increased atherosclerosis. Circulation 112: 879-884.

89. Ayyobi AF, McGladdery SH, Chan S, John Mancini GB, Hill JS, et al. (2004) Lecithin: cholesterol acyltransferase (LCAT) deficiency and risk of vascular disease: 25 year follow-up. Atherosclerosis 177: 361-366.

90. Calabresi L, Baldassarre D, Castelnuovo S, Conca P, Bocchi L, et al. (2009) Functional lecithin: cholesterol acyltransferase is not required for efficient atheroprotection in humans. Circulation 120: 628-635.
91. Savel J, Lafitte M, Pucheu Y, Pradeau V, Tabarin A, et al. (2012) Very low levels of HDL cholesterol and atherosclerosis, a variable relationship--a review of LCAT deficiency. Vasc Health Risk Manag 8: 357-361.

92. Rousset X, Vaisman B, Auerbach B, Krause BR, Homan R, et al. (2010) Effect of recombinant human lecithin cholesterol acyltransferase infusion on lipoprotein metabolism in mice. J Pharmacol Exp Ther 335: 140-148.

93. Kunnen S, Van Eck M (2012) Lecithin:cholesterol acyltransferase: old friend or foe in atherosclerosis? J Lipid Res 53: 1783-1799.

94. Stafforini DM (2009) Biology of platelet-activating factor acetylhydrolase (PAF-AH, lipoprotein associated phospholipase A2). Cardiovasc Drugs Ther 23: 73-83.

95. Tjoelker LW, Wilder C, Eberhardt C, Stafforini DM, Dietsch G, et al. (1995) Anti-inflammatory properties of a platelet-activating factor acetylhydrolase. Nature 374: 549-553.

96. Theilmeier G, De Geest B, Van Veldhoven PP, Stengel D, Michiels C, et al. (2000) HDL-associated PAF-AH reduces endothelial adhesiveness in apoE-/- mice. FASEB journal: official publication of the Federation of American Societies for Experimental Biology 14: 2032-2039.

97. Quarck R, De Geest B, Stengel D, Mertens A, Lox M, et al. (2001) Adenovirus-mediated gene transfer of human platelet-activating factoracetylhydrolase prevents injury-induced neointima formation and reduces spontaneous atherosclerosis in apolipoprotein E-deficient mice. Circulation 103: 2495-2500.

98. Hakkinen T, Luoma JS, Hiltunen MO, Macphee $\mathrm{CH}$, Milliner KJ, et al. (1999) Lipoprotein-associated phospholipase A (2), platelet-activating factor acetylhydrolase, is expressed by macrophages in human and rabbit atherosclerotic lesions. Arteriosclerosis, thrombosis, and vascular biology 19: 2909-2917.

99. Kolodgie FD, Burke AP, Skorija KS, Ladich E, Kutys R, et al. (2006) Lipoprotein-associated phospholipase A2 protein expression in the natural progression of human coronary atherosclerosis. Arterioscler Thromb Vasc Biol 26: 2523-2529.

100. Lp-PLA(2) Studies Collaboration, Thompson A, Gao P, Orfei L, Watson $S$, et al. (2010) Lipoprotein-associated phospholipase A(2) and risk of coronary disease, stroke, and mortality: collaborative analysis of 32 prospective studies. Lancet 375: 1536-1544.

101. Zhang H, Zhang J, Shen D, Zhang L, He F, et al. (2013) Lentiviralmediated RNA interference of lipoprotein-associated phospholipase A2 ameliorates inflammation and atherosclerosis in apolipoprotein Edeficient mice. Int J Mol Med 31: 651-659.

102. Wilensky RL, Shi Y, Mohler ER, 3rd, Hamamdzic D, Burgert ME, et al. (2008) Inhibition of lipoprotein-associated phospholipase A2 reduces complex coronary atherosclerotic plaque development. Nature medicine 14: 1059-1066.

103. Leite JO, Vaishnav U, Puglisi M, Fraser H, Trias J, et al. (2009) A-002 (Varespladib), a phospholipase A2 inhibitor, reduces atherosclerosis in guinea pigs. BMC Cardiovasc Disord 9: 7.

104. STABILITY Investigators, White HD, Held C, Stewart R, Tarka E, et al. (2014) Darapladib for preventing ischemic events in stable coronary heart disease. N Engl J Med 370: 1702-1711.

105. O'Donoghue ML, Braunwald E, White HD, Lukas MA, Tarka E, et al. (2014) Effect of darapladib on major coronary events after an acute coronary syndrome: the SOLID-TIMI 52 randomized clinical trial. JAMA 312: 1006-1015.

106. Nicholls SJ, Kastelein JJ, Schwartz GG, Bash D, Rosenson RS, et al. (2014) Varespladib and cardiovascular events in patients with an acute coronary syndrome: the VISTA-16 randomized clinical trial. JAMA 311: 252-262.

107. Polfus LM, Gibbs RA, Boerwinkle E (2015) Coronary heart disease and genetic variants with low phospholipase A2 activity. N Engl J Med 372: 295-296.

108. Abifadel M, Varret M, Rabes JP, Allard D, Ouguerram K, et al. (2003) Mutations in PCSK9 cause autosomal dominant hypercholesterolemia. Nat Genet 34: 154-156.

109. Benjannet S, Rhainds D, Essalmani R, Mayne J, Wickham L, et al. (2004) NARC-1/PCSK9 and its natural mutants: zymogen cleavage and effects 
on the low density lipoprotein (LDL) receptor and LDL cholesterol. J Biol Chem 279: 48865-48875.

110. Seidah NG, Benjannet S, Wickham L, Marcinkiewicz J, Jasmin SB, et al. (2003) The secretory proprotein convertase neural apoptosis-regulated convertase 1 (NARC-1): liver regeneration and neuronal differentiation. Proc Natl Acad Sci U S A 100: 928-933.

111. Lee R, Channon KM, Antoniades C (2012) Therapeutic strategies targeting endothelial function in humans: clinical implications. Curr Vasc Pharmacol 10: 77-93.

112. Montezano AC, Touyz RM (2012) Reactive oxygen species and endothelial function--role of nitric oxide synthase uncoupling and Nox family nicotinamide adenine dinucleotide phosphate oxidases. Basic Clin Pharmacol Toxicol 110: 87-94.

113. Nishino T, Okamoto K, Eger BT, Pai EF, Nishino T (2008) Mammalian xanthine oxidoreductase - mechanism of transition from xanthine dehydrogenase to xanthine oxidase. FEBS J 275: 3278-3289.

114. Manea A (2010) NADPH oxidase-derived reactive oxygen species: involvement in vascular physiology and pathology. Cell Tissue Res 342: 325-339.

115. Drummond GR, Sobey CG2 (2014) Endothelial NADPH oxidases: which NOX to target in vascular disease? Trends Endocrinol Metab 25: 452-463.

116. Maitra U, Singh N, Gan L, Ringwood L, Li L (2009) IRAK-1 contributes to lipopolysaccharide-induced reactive oxygen species generation in macrophages by inducing NOX-1 transcription and Racl activation and suppressing the expression of antioxidative enzymes. J Biol Chem 284: 35403-35411.

117. Manea A, Manea SA, Gan AM, Constantin A, Fenyo IM, et al. (2015) Human monocytes and macrophages express NADPH oxidase 5; a potential source of reactive oxygen species in atherosclerosis. Biochem Biophys Res Commun 461: 172-179.

118. Rivera J, Sobey CG, Walduck AK, Drummond GR (2010) Nox isoforms in vascular pathophysiology: insights from transgenic and knockout mouse models. Redox Rep 15: 50-63.

119. Niu XL, Madamanchi NR, Vendrov AE, Tchivilev I, Rojas M, et al. (2010) Nox activator 1: a potential target for modulation of vascular reactive oxygen species in atherosclerotic arteries. Circulation 121: 549-559.

120. Vendrov AE, Madamanchi NR, Niu XL, Molnar KC, Runge M, et al. (2010) NADPH oxidases regulate CD44 and hyaluronic acid expression in thrombin-treated vascular smooth muscle cells and in atherosclerosis. The Journal of biological chemistry 285: 26545-26557.

121. Kinkade K, Streeter J, Miller FJ (2013) Inhibition of NADPH oxidase by apocynin attenuates progression of atherosclerosis. Int J Mol Sci 14: 17017-17028.

122. Kirk EA, Dinauer MC, Rosen H, Chait A, Heinecke JW, et al. (2000) Impaired superoxide production due to a deficiency in phagocyte NADPH oxidase fails to inhibit atherosclerosis in mice. Arterioscler Thromb Vasc Biol 20: 1529-1535.

123. Judkins CP, Diep H, Broughton BR, Mast AE, Hooker EU, et al. (2010) Direct evidence of a role for Nox2 in superoxide production, reduced nitric oxide bioavailability, and early atherosclerotic plaque formation in ApoE-/- mice. Am J Physiol Heart Circ Physiol 298: H24-32.

124. Hsich E, Segal BH, Pagano PJ, Rey FE, Paigen B, et al. (2000) Vascular effects following homozygous disruption of $\mathrm{p} 47$ (phox) : An essential component of NADPH oxidase. Circulation 101: 1234-1236.

125. Vendrov AE, Hakim ZS, Madamanchi NR, Rojas M, Madamanchi C, et al. (2007) Atherosclerosis is attenuated by limiting superoxide generation in both macrophages and vessel wall cells. Arterioscler Thromb Vasc Biol 27: 2714-2721.

126. Sheehan AL, Carrell S, Johnson B, Stanic B, Banfi B, et al. (2011) Role for Nox1 NADPH oxidase in atherosclerosis. Atherosclerosis 216: 321-326.

127. Ferreiro CR, Chagas AC, Carvalho MH, Dantas AP, Scavone C, et al. (2004) Expression of inducible nitric oxide synthase is increased in patients with heart failure due to ischemic disease. Braz J Med Biol Res 37: 1313-1320.
128. Dias RG, Negrão CE, Krieger $M H$ (2011) Nitric oxide and the cardiovascular system: cell activation, vascular reactivity and genetic variant. Arq Bras Cardiol 96: 68-75.

129. Shaul PW, Anderson RG (1998) Role of plasmalemmal caveolae in signal transduction. Am J Physiol 275: L843-851.

130. Bucci M, Gratton JP, Rudic RD, Acevedo L, Roviezzo F, et al. (2000) In vivo delivery of the caveolin-1 scaffolding domain inhibits nitric oxide synthesis and reduces inflammation. Nat Med 6: 1362-1367.

131. Heltianu C, Costache G, Gafencu A, Diaconu M, Bodeanu M, et al. (2005) Relationship of eNOS gene variants to diseases that have in common an endothelial cell dysfunction. J Cell Mol Med 9: 135-142.

132. Takimoto E, Champion HC, Li M, Ren S, Rodriguez ER, et al. (2005) Oxidant stress from nitric oxide synthase-3 uncoupling stimulates cardiac pathologic remodeling from chronic pressure load. J Clin Invest 115: 1221-1231.

133. Kim JH, Bugaj LJ, Oh YJ, Bivalacqua TJ, Ryoo S, et al. (2009) Arginase inhibition restores NOS coupling and reverses endothelial dysfunction and vascular stiffness in old rats. J Appl Physiol (1985) 107: 1249-1257.

134. van Etten RW, de Koning EJ, Verhaar MC, Gaillard CA, Rabelink TJ (2002) Impaired NO-dependent vasodilation in patients with Type II (non-insulin-dependent) diabetes mellitus is restored by acute administration of folate. Diabetologia 45: 1004-1010.

135. Shears LL 2nd, Kibbe MR, Murdock AD, Billiar TR, Lizonova A, et al. (1998) Efficient inhibition of intimal hyperplasia by adenovirus-mediated inducible nitric oxide synthase gene transfer to rats and pigs in vivo. J Am Coll Surg 187: 295-306.

136. Valdivia A, Pérez-Alvarez S, Aroca-Aguilar JD, Ikuta I, Jordán J (2009) Superoxide dismutases: a physiopharmacological update. J Physiol Biochem 65: 195-208.

137. Sentman ML, Brännström T, Westerlund S, Laukkanen MO, YläHerttuala S, et al. (2001) Extracellular superoxide dismutase deficiency and atherosclerosis in mice. Arterioscler Thromb Vasc Biol 21: 1477-1482.

138. Ozumi K, Tasaki H, Takatsu H, Nakata S, Morishita T, et al. (2005) Extracellular superoxide dismutase overexpression reduces cuff-induced arterial neointimal formation. Atherosclerosis 181: 55-62.

139. Bräsen JH, Leppänen $\mathrm{O}$, Inkala M, Heikura T, Levin M, et al. (2007) Extracellular superoxide dismutase accelerates endothelial recovery and inhibits in-stent restenosis in stented atherosclerotic Watanabe heritable hyperlipidemic rabbit aorta. J Am Coll Cardiol 50: 2249-2253.

140. Ohashi M, Runge MS, Faraci FM, Heistad DD (2006) MnSOD deficiency increases endothelial dysfunction in ApoE-deficient mice. Arterioscler Thromb Vasc Biol 26: 2331-2336.

141. Yang H, Roberts LJ, Shi MJ, Zhou LC, Ballard BR, et al. (2004) Retardation of atherosclerosis by overexpression of catalase or both $\mathrm{Cu} / \mathrm{Zn}$-superoxide dismutase and catalase in mice lacking apolipoprotein E. Circ Res 95: 1075-1081.

142. Wu X, Kang J, Xie C, Burris R, Ferguson ME, et al. (2010) Dietary blueberries attenuate atherosclerosis in apolipoprotein E-deficient mice by upregulating antioxidant enzyme expression. J Nutr 140: 1628-1632.

143. Jiang F, Guo Y, Salvemini D, Dusting GJ (2003) Superoxide dismutase mimetic M40403 improves endothelial function in apolipoprotein(E)deficient mice. Br J Pharmacol 139: 1127-1134.

144. Wang HH, Hung TM, Wei J, Chiang AN (2004) Fish oil increases antioxidant enzyme activities in macrophages and reduces atherosclerotic lesions in apoE-knockout mice. Cardiovasc Res 61: 169-176.

145. Burris RL, Xie CH, Thampi P, Wu X, Melnyk SB, et al. (2010) Dietary rice protein isolate attenuates atherosclerosis in apoE-deficient mice by upregulating antioxidant enzymes. Atherosclerosis 212: 107-115.

146. Yang H, Zhou L, Wang Z, Roberts LJ 2nd, Lin X, et al. (2009) Overexpression of antioxidant enzymes in ApoE-deficient mice suppresses benzo(a)pyrene-accelerated atherosclerosis. Atherosclerosis 207: 51-58. 
147. Bangash M (1975) Symptomatic aneurysm of the abdominal aorta: successful surgery in elderly patients, one with a massive aneurysm. Vasc Surg 9: 25-28.

148. Heistad DD1 (2006) Gene therapy for vascular disease. Vascul Pharmacol 45: 331-333.

149. Torzewski M, Ochsenhirt V, Kleschyov AL, Oelze M, Daiber A, et al. (2007) Deficiency of glutathione peroxidase-1 accelerates the progression of atherosclerosis in apolipoprotein E-deficient mice. Arterioscler Thromb Vasc Biol 27: 850-857.

150. de Haan JB, Witting PK, Stefanovic N, Pete J, Daskalakis M, et al. (2006) Lack of the antioxidant glutathione peroxidase-1 does not increase atherosclerosis in C57BL/J6 mice fed a high-fat diet. J Lipid Res 47: 1157-1167.

151. Espinola-Klein C, Rupprecht HJ, Bickel C, Schnabel R, Genth-Zotz S, et al. (2007) Glutathione peroxidase-1 activity, atherosclerotic burden, and cardiovascular prognosis. Am J Cardiol 99: 808-812.

152. de Bem AF, Farina M, Portella Rde L, Nogueira CW, Dinis TC, et al. (2008) Diphenyl diselenide, a simple glutathione peroxidase mimetic, inhibits human LDL oxidation in vitro. Atherosclerosis 201: 92-100.

153. Hort MA, Straliotto MR, Netto PM, da Rocha JB, de Bem AF, et al. (2011) Diphenyl diselenide effectively reduces atherosclerotic lesions in LDLr -/- mice by attenuation of oxidative stress and inflammation. J Cardiovasc Pharmacol 58: 91-101.

154. Lubos E, Loscalzo J, Handy DE (2011) Glutathione peroxidase-1 in health and disease: from molecular mechanisms to therapeutic opportunities. Antioxid Redox Signal 15: 1957-1997.

155. Morse D, Choi AM (2005) Heme oxygenase-1: from bench to bedside. Am J Respir Crit Care Med 172: 660-670.

156. Yachie A, Niida Y, Wada T, Igarashi N, Kaneda H, et al. (1999) Oxidative stress causes enhanced endothelial cell injury in human heme oxygenase-1 deficiency. J Clin Invest 103: 129-135.

157. Radhakrishnan N, Yadav SP, Sachdeva A, Pruthi PK, Sawhney S, et al. (2011) Human heme oxygenase-1 deficiency presenting with hemolysis, nephritis, and asplenia. J Pediatr Hematol Oncol 33: 74-78.

158. Poss KD, Tonegawa S (1997) Heme oxygenase 1 is required for mammalian iron reutilization. Proc Natl Acad Sci U S A 94: 10919-10924.

159. Poss KD, Tonegawa S (1997) Reduced stress defense in heme oxygenase 1-deficient cells. Proc Natl Acad Sci U S A 94: 10925-10930.

160. Yet SF, Perrella MA, Layne MD, Hsieh CM, Maemura K, et al. (1999) Hypoxia induces severe right ventricular dilatation and infarction in heme oxygenase-1 null mice. J Clin Invest 103: R23-29.

161. Yoshida T, Maulik N, Ho YS, Alam J, Das DK (2001) H(mox-1) constitutes an adaptive response to effect antioxidant cardioprotection: A study with transgenic mice heterozygous for targeted disruption of the Heme oxygenase-1 gene. Circulation 103: 1695-1701.

162. Bach FH1 (2002) Heme oxygenase-1 as a protective gene. Wien Klin Wochenschr 114 Suppl 4: 1-3.

163. Watari Y, Yamamoto Y, Brydun A, Ishida T, Mito S, et al. (2008) Ablation of the bach1 gene leads to the suppression of atherosclerosis in bach1 and apolipoprotein E double knockout mice. Hypertens Res 31: 783-792.

164. Ishikawa K, Sugawara D, Wang Xp, Suzuki K, Itabe H, et al. (2001) Heme oxygenase-1 inhibits atherosclerotic lesion formation in ldl-receptor knockout mice. Circ Res 88: 506-512.

165. Liu XM, Azam MA, Peyton KJ, Ensenat D, Keswani AN, et al. (2007) Butylated hydroxyanisole stimulates heme oxygenase-1 gene expression and inhibits neointima formation in rat arteries. Cardiovasc Res 74 : 169-179.

166. Durante W1 (2010) Targeting heme oxygenase-1 in vascular disease Curr Drug Targets 11: 1504-1516.

167. Harel M, Aharoni A, Gaidukov L, Brumshtein B, Khersonsky O, et al (2004) Structure and evolution of the serum paraoxonase family of detoxifying and anti-atherosclerotic enzymes. Nat Struct Mol Biol 11: 412-419.
168. Aviram M, Rosenblat M, Bisgaier CL, Newton RS, Primo-Parmo SL, et al. (1998) Paraoxonase inhibits high-density lipoprotein oxidation and preserves its functions. A possible peroxidative role for paraoxonase. J Clin Invest 101: 1581-1590.

169. Deakin SP, Bioletto S, Bochaton-Piallat ML, James RW (2011) HDLassociated paraoxonase-1 can redistribute to cell membranes and influence sensitivity to oxidative stress. Free Radic Biol Med 50: 102-109.

170. Shih DM, Gu L, Xia YR, Navab M, Li WF, et al. (1998) Mice lacking serum paraoxonase are susceptible to organophosphate toxicity and atherosclerosis. Nature 394: 284-287.

171. Tward A, Xia YR, Wang XP, Shi YS, Park C, et al. (2002) Decreased atherosclerotic lesion formation in human serum paraoxonase transgenic mice. Circulation 106: 484-490.

172. Mackness B, Quarck R, Verreth W, Mackness M, Holvoet P (2006) Human paraoxonase-1 overexpression inhibits atherosclerosis in a mouse model of metabolic syndrome. Arterioscler Thromb Vasc Biol 26: 1545-1550.

173. Rozenberg O, Shih DM, Aviram M (2005) Paraoxonase 1 (PON1) attenuates macrophage oxidative status: studies in PON1 transfected cells and in PON1 transgenic mice. Atherosclerosis 181: 9-18.

174. Guns PJ, Van Assche T, Verreth W, Fransen P, Mackness B, et al. (2008) Paraoxonase 1 gene transfer lowers vascular oxidative stress and improves vasomotor function in apolipoprotein E-deficient mice with pre-existing atherosclerosis. Br J Pharmacol 153: 508-516.

175. Bhattacharyya T, Nicholls SJ, Topol EJ, Zhang R, Yang X, et al. (2008) Relationship of paraoxonase 1 (PON1) gene polymorphisms and functional activity with systemic oxidative stress and cardiovascular risk. JAMA 299: 1265-1276.

176. Mackness B, Durrington P, McElduff P, Yarnell J, Azam N, et al. (2003) Low paraoxonase activity predicts coronary events in the Caerphilly Prospective Study. Circulation 107: 2775-2779.

177. van Himbergen TM, van der Schouw YT, Voorbij HA, van Tits LJ, Stalenhoef AF, et al. (2008) Paraoxonase (PON1) and the risk for coronary heart disease and myocardial infarction in a general population of Dutch women. Atherosclerosis 199: 408-414.

178. Mackness B, Hunt R, Durrington PN, Mackness MI (1997) Increased immunolocalization of paraoxonase, clusterin, and apolipoprotein A-I in the human artery wall with the progression of atherosclerosis. Arterioscler Thromb Vasc Biol 17: 1233-1238.

179. Jakubowski H1 (2000) Calcium-dependent human serum homocysteine thiolactone hydrolase. A protective mechanism against protein $\mathrm{N}$ homocysteinylation. J Biol Chem 275: 3957-3962.

180. Abelló D, Sancho E, Camps J3, Joven J4 (2014) Exploring the role of paraoxonases in the pathogenesis of coronary artery disease: a systematic review. Int J Mol Sci 15: 20997-21010.

181. Wheeler JG, Keavney BD, Watkins H, Collins R, Danesh J (2004) Four paraoxonase gene polymorphisms in 11212 cases of coronary heart disease and 12786 controls: meta-analysis of 43 studies. Lancet 363: 689-695.

182. Ceron JJ, Tecles F, Tvarijonaviciute A (2014) Serum paraoxonase 1 (PON1) measurement: an update. BMC Vet Res 10: 74.

183. Camps J, Marsillach J, Joven J (2009) The paraoxonases: role in human diseases and methodological difficulties in measurement. Crit Rev Clin Lab Sci 46: 83-106.

184. Raffetto JD, Khalil RA (2008) Matrix metalloproteinases and their inhibitors in vascular remodeling and vascular disease. Biochem Pharmacol 75: 346-359.

185. Galis ZS, Sukhova GK, Kranzhöfer R, Clark S, Libby P (1995) Macrophage foam cells from experimental atheroma constitutively produce matrix-degrading proteinases. Proc Natl Acad Sci U S A 92: 402-406.

186. Jeng AY, Chou M, Sawyer WK, Caplan SL, Von Linden-Reed J, et al. (1999) Enhanced expression of matrix metalloproteinase-3, -1, and -13 mRNAs in the aortas of apolipoprotein E-deficient mice with advanced atherosclerosis. Ann N Y Acad Sci 878: 555-558. 
187. Mulder H1 (2011) Matrix metalloproteinases: keys to healthier blood vessels in diabetes? J Endocrinol 210: 1-2.

188. Sini S, Deepa D, Harikrishnan S3, Jayakumari N4 (2014) Evidence for an exclusive association of matrix metalloproteinase-9 with dysfunctional high-density lipoprotein: a novel finding. Atherosclerosis 236: 162-168.

189. Johnson JL, Jenkins NP, Huang WC, Di Gregoli K, Sala-Newby GB, et al. (2014) Relationship of MMP-14 and TIMP-3 expression with macrophage activation and human atherosclerotic plaque vulnerability. Mediators Inflamm 2014: 276457.

190. Yoon YW, Kwon HM, Hwang KC, Choi EY, Hong BK, et al. (2005) Upstream regulation of matrix metalloproteinase by EMMPRIN; extracellular matrix metalloproteinase inducer in advanced atherosclerotic plaque. Atherosclerosis 180: 37-44.

191. Seizer P, Schönberger T, Schött M, Lang MR, Langer HF, et al. (2010) EMMPRIN and its ligand cyclophilin A regulate MT1-MMP, MMP-9 and M-CSF during foam cell formation. Atherosclerosis 209: 51-57.

192. Sasaki T, Nakamura K, Sasada K, Okada S, Cheng XW, et al. (2013) Matrix metalloproteinase-2 deficiency impairs aortic atherosclerotic calcification in ApoE-deficient mice. Atherosclerosis 227: 43-50.

193. Rouis M, Adamy C, Duverger N, Lesnik P, Horellou P, et al. (1999) Adenovirus-mediated overexpression of tissue inhibitor of metalloproteinase-1 reduces atherosclerotic lesions in apolipoprotein Edeficient mice. Circulation 100: 533-540.

194. Johnson JL, Fritsche-Danielson R, Behrendt M, Westin-Eriksson A, Wennbo $\mathrm{H}$, et al. (2006) Effect of broad-spectrum matrix metalloproteinase inhibition on atherosclerotic plaque stability. Cardiovasc Res 71: 586-595.

195. Pawlowska M, Gajda M, Pyka-Fosciak G, Toton-Zuranska J, Niepsuj A et al. (2011) The effect of doxycycline on atherogenesis in apoE-knockout mice. J Physiol Pharmacol 62: 247-250.

196. Johnson JL, Devel L, Czarny B, George SJ, Jackson CL, et al. (2011) A selective matrix metalloproteinase-12 inhibitor retards atherosclerotic plaque development in apolipoprotein E-knockout mice. Arterioscler Thromb Vasc Biol 31: 528-535.

197. Quillard T, Tesmenitsky Y, Croce K, Travers R, Shvartz E, et al. (2011) Selective inhibition of matrix metalloproteinase-13 increases collagen content of established mouse atherosclerosis. Arterioscler Thromb Vasc Biol 31: 2464-2472.

198. Newby AC1 (2014) Proteinases and plaque rupture: unblocking the road to translation. Curr Opin Lipidol 25: 358-366.

199. Liu H, Yang LX, Guo RW, Zhu GF, Shi YK, et al. (2013) Functional blockage of EMMPRIN ameliorates atherosclerosis in apolipoprotein Edeficient mice. Int J Cardiol 168: 3248-3253.

200. Liu D, Ji L, Wang Y, Zheng L (2012) Cyclooxygenase-2 expression, prostacyclin production and endothelial protection of high-density lipoprotein. Cardiovasc Hematol Disord Drug Targets 12: 98-105.

201. Kurumbail RG, Stevens AM, Gierse JK, McDonald JJ, Stegeman RA, et al. (1996) Structural basis for selective inhibition of cyclooxygenase- 2 by anti-inflammatory agents. Nature 384: 644-648.

202. Amer M, Bead VR, Bathon J, Blumenthal RS, Edwards DN (2010) Use of nonsteroidal anti-inflammatory drugs in patients with cardiovascular disease: a cautionary tale. Cardiol Rev 18: 204-212.

203. McClelland S, Gawaz M, Kennerknecht E, Konrad CS, Sauer S, et al. (2009) Contribution of cyclooxygenase-1 to thromboxane formation, platelet-vessel wall interactions and atherosclerosis in the ApoE null mouse. Atherosclerosis 202: 84-91.

204. Babaev VR, Ding L, Reese J, Morrow JD, Breyer MD, et al. (2006) Cyclooxygenase-1 deficiency in bone marrow cells increases early atherosclerosis in apolipoprotein E- and low-density lipoprotein receptor-null mice. Circulation 113: 108-117.

205. Jacob S, Laury-Kleintop L, Lanza-Jacoby S (2008) The select cyclooxygenase-2 inhibitor celecoxib reduced the extent of atherosclerosis in apo E-/- mice. J Surg Res 146: 135-142.

206. Linton MF, Fazio S (2002) Cyclooxygenase-2 and atherosclerosis. Curr Opin Lipidol 13: 497-504.
207. Yu Z, Crichton I, Tang SY, Hui Y, Ricciotti E, et al. (2012) Disruption of the 5-lipoxygenase pathway attenuates atherogenesis consequent to COX-2 deletion in mice. Proc Natl Acad Sci U S A 109: 6727-6732.

208. Narasimha AJ, Watanabe J, Ishikawa TO, Priceman SJ, Wu L, et al. (2010) Absence of myeloid COX-2 attenuates acute inflammation but does not influence development of atherosclerosis in apolipoprotein $\mathrm{E}$ null mice. Arterioscler Thromb Vasc Biol 30: 260-268.

209. Hui Y, Ricciotti E, Crichton I, Yu Z, Wang D, et al. (2010) Targeted deletions of cyclooxygenase- 2 and atherogenesis in mice. Circulation 121 : 2654-2660.

210. Tang SY, Monslow J, Todd L, Lawson J, Puré E, et al. (2014) Cyclooxygenase-2 in endothelial and vascular smooth muscle cells restrains atherogenesis in hyperlipidemic mice. Circulation 129: 1761-1769.

211. Albert D, Zündorf I, Dingermann T, Müller WE, Steinhilber D, et al. (2002) Hyperforin is a dual inhibitor of cyclooxygenase-1 and 5lipoxygenase. Biochem Pharmacol 64: 1767-1775.

212. O'Leary KA, de Pascual-Teresa S, Needs PW, Bao YP, O'Brien NM, et al. (2004) Effect of flavonoids and vitamin E on cyclooxygenase-2 (COX-2) transcription. Mutat Res 551: 245-254.

213. Cicero AF, Derosa G, Gaddi A (2005) Combined lipoxygenase/cyclooxygenase inhibition in the elderly: the example of licofelone. Drugs Aging 22: 393-403.

214. Floyd CN, Ferro A2 (2014) Mechanisms of aspirin resistance. Pharmacol Ther 141: 69-78.

215. Zhao L, Funk CD (2004) Lipoxygenase pathways in atherogenesis. Trends Cardiovasc Med 14: 191-195.

216. Huo Y, Zhao L, Hyman MC, Shashkin P, Harry BL, et al. (2004) Critical role of macrophage 12/15-lipoxygenase for atherosclerosis in apolipoprotein E-deficient mice. Circulation 110: 2024-2031.

217. George J, Afek A, Shaish A, Levkovitz H, Bloom N, et al. (2001) 12/15Lipoxygenase gene disruption attenuates atherogenesis in LDL receptordeficient mice. Circulation 104: 1646-1650.

218. Poeckel D, Zemski Berry KA, Murphy RC, Funk CD (2009) Dual 12/15and 5-lipoxygenase deficiency in macrophages alters arachidonic acid metabolism and attenuates peritonitis and atherosclerosis in ApoE knock-out mice. J Biol Chem 284: 21077-21089.

219. Pergola C, Dodt G, Rossi A, Neunhoeffer E, Lawrenz B, et al. (2008) ERK-mediated regulation of leukotriene biosynthesis by androgens: a molecular basis for gender differences in inflammation and asthma. Proc Natl Acad Sci U S A 105: 19881-19886.

220. Zhao L, Praticò D, Rader DJ, Funk CD (2005) 12/15-Lipoxygenase gene disruption and vitamin $\mathrm{E}$ administration diminish atherosclerosis and oxidative stress in apolipoprotein $\mathrm{E}$ deficient mice through a final common pathway. Prostaglandins Other Lipid Mediat 78: 185-193.

221. Ghazalpour A, Wang X, Lusis AJ, Mehrabian M (2006) Complex inheritance of the 5-lipoxygenase locus influencing atherosclerosis in mice. Genetics 173: 943-951.

222. Lane KTBeese LS (2006) Thematic review series: lipid posttranslational modifications. Structural biology of protein farnesyltransferase and geranylgeranyltransferase type I. Journal of lipid research 47: 681-699.

223. Xu N, Shen N, Wang X, Jiang S, Xue B, et al. (2015) Protein prenylation and human diseases: a balance of protein farnesylation and geranylgeranylation. Sci China Life Sci 58: 328-335.

224. Shen M, Pan P, Li Y, Li D3, Yu H4, et al. (2015) Farnesyltransferase and geranylgeranyltransferase I: structures, mechanism, inhibitors and molecular modeling. Drug Discov Today 20: 267-276.

225. Mijimolle N, Velasco J, Dubus P, Guerra C, Weinbaum CA, et al. (2005) Protein farnesyltransferase in embryogenesis, adult homeostasis, and tumor development. Cancer Cell 7: 313-324.

226. Draznin B1 (2010) Mitogenic action of insulin: friend, foe or 'frenemy'? Diabetologia 53: 229-233.

227. McClintock D, Gordon LB, Djabali K (2006) Hutchinson-Gilford progeria mutant lamin A primarily targets human vascular cells as 
detected by an anti-Lamin A G608G antibody. Proc Natl Acad Sci U S A 103: 2154-2159.

228. Pacheco LM, Gomez LA, Dias J3, Ziebarth NM3, Howard GA4, et al. (2014) Progerin expression disrupts critical adult stem cell functions involved in tissue repair. Aging (Albany NY) 6: 1049-1063.

229. Kane MS, Lindsay ME, Judge DP, Barrowman J, Ap Rhys C, et al. (2013) LMNA-associated cardiocutaneous progeria: an inherited autosomal dominant premature aging syndrome with late onset. Am J Med Genet A 161A: 1599-1611.

230. Gordon LB, Kleinman ME, Miller DT, Neuberg DS, Giobbie-Hurder A, et al. (2012) Clinical trial of a farnesyltransferase inhibitor in children with Hutchinson-Gilford progeria syndrome. Proc Natl Acad Sci U S A 109: 16666-16671.

231. Sugita M, Sugita H, Kaneki M (2007) Farnesyltransferase inhibitor, manumycin a, prevents atherosclerosis development and reduces oxidative stress in apolipoprotein E-deficient mice. Arterioscler Thromb Vasc Biol 27: 1390-1395.

232. Nikolov IG, Joki N, Galmiche A, Nguyen-Khoa T, Guerrera IC, et al. (2013) Farnesyltransferase inhibitor R115777 protects against vascular disease in uremic mice. Atherosclerosis 229: 42-51.

233. Coats P, Kennedy S, Pyne S, Wainwright CL, Wadsworth RM (2008) Inhibition of non-Ras protein farnesylation reduces in-stent restenosis. Atherosclerosis 197: 515-523.

234. Cohen LH, Pieterman E, van Leeuwen RE, Overhand M, Burm BE, et al. (2000) Inhibitors of prenylation of Ras and other G-proteins and their application as therapeutics. Biochem Pharmacol 60: 1061-1068.

235. Mattingly RR, Gibbs RA, Menard RE, Reiners JJ, Jr. (2002) Potent suppression of proliferation of a10 vascular smooth muscle cells by combined treatment with lovastatin and 3-allylfarnesol, an inhibitor of protein farnesyltransferase. The Journal of pharmacology and experimental therapeutics 303: 74-81.

236. El Oualid F, Cohen LH, van der Marel GA, Overhand M (2006) Inhibitors of protein: geranylgeranyl transferases. Curr Med Chem 13: 2385-2427.

237. Khan OM, Akula MK, Skålen K, Karlsson C, Ståhlman M, et al. (2013) Targeting GGTase-I activates RHOA, increases macrophage reverse cholesterol transport, and reduces atherosclerosis in mice. Circulation 127: 782-790.

238. Dimitrova Y, Dunoyer-Geindre S, Reber G, Mach F, Kruithof EK, et al. (2003) Effects of statins on adhesion molecule expression in endothelial cells. J Thromb Haemost 1: 2290-2299.

239. Asai A, Okajima F, Nakajima Y, Nagao M, Nakagawa K, et al. (2011) Involvement of Rac GTPase activation in phosphatidylcholine hydroperoxide-induced THP-1 cell adhesion to ICAM-1. Biochem Biophys Res Commun 406: 273-277.

240. Kofler S, Schlichting C, Jankl S, Nickel T, Weis M (2008) Dual mode of HMG-CoA reductase inhibition on dendritic cell invasion. Atherosclerosis 197: 105-110.

241. Byrne MM, Murphy RT, Ryan AW1 (2014) Epigenetic modulation in the treatment of atherosclerotic disease. Front Genet 5: 364.

242. Choudhary C, Kumar C, Gnad F, Nielsen ML, Rehman M, et al. (2009) Lysine acetylation targets protein complexes and co-regulates major cellular functions. Science 325: 834-840.

243. de Ruijter AJ, van Gennip AH, Caron HN, Kemp S, van Kuilenburg AB (2003) Histone deacetylases (HDACs): characterization of the classical HDAC family. Biochem J 370: 737-749.

244. Drummond DC, Noble CO, Kirpotin DB, Guo Z, Scott GK, et al. (2005) Clinical development of histone deacetylase inhibitors as anticancer agents. Annu Rev Pharmacol Toxicol 45: 495-528.

245. Behera J, Jayprakash V, Sinha BN1 (2015) Histone deacetylase inhibitors: a review on class-I specific inhibition. Mini Rev Med Chem 15: 731-750.

246. Zheng XX, Zhou T, Wang XA, Tong XH, Ding JW2 (2015) Histone deacetylases and atherosclerosis. Atherosclerosis 240: 355-366.

247. Lehmann LH, Worst BC, Stanmore DA, Backs J (2014) Histone deacetylase signaling in cardioprotection. Cell Mol Life Sci 71: 1673-1690.
248. Montgomery RL, Davis CA, Potthoff MJ, Haberland M, Fielitz J, et al. (2007) Histone deacetylases 1 and 2 redundantly regulate cardiac morphogenesis, growth, and contractility. Genes Dev 21: 1790-1802.

249. Trivedi CM, Lu MM, Wang Q, Epstein JA (2008) Transgenic overexpression of Hdac3 in the heart produces increased postnatal cardiac myocyte proliferation but does not induce hypertrophy. J Biol Chem 283: 26484-26489.

250. Wang ZY, Qin W, Yi F1 (2015) Targeting histone deacetylases: perspectives for epigenetic-based therapy in cardio-cerebrovascular disease. J Geriatr Cardiol 12: 153-164.

251. Høgh Kølbæk Kjær AS, Brinkmann CR, Dinarello CA, Olesen R, Østergaard L, et al. (2015) The histone deacetylase inhibitor panobinostat lowers biomarkers of cardiovascular risk and inflammation in HIV patients. AIDS 29: 1195-1200.

252. Zampetaki A, Zeng L, Margariti A, Xiao Q, Li H, et al. (2010) Histone deacetylase 3 is critical in endothelial survival and atherosclerosis development in response to disturbed flow. Circulation 121: 132-142.

253. Hoeksema MA, Gijbels MJ, Van den Bossche J, van der Velden S, Sijm A, et al. (2014) Targeting macrophage Histone deacetylase 3 stabilizes atherosclerotic lesions. EMBO Mol Med 6: 1124-1132.

254. Xu F, Mao C, Ding Y, Rui C, Wu L, et al. (2010) Molecular and enzymatic profiles of mammalian DNA methyltransferases: structures and targets for drugs. Curr Med Chem 17: 4052-4071.

255. Geisel J, Schorr H, Bodis M, Isber S, Hübner U, et al. (2005) The vegetarian lifestyle and DNA methylation. Clin Chem Lab Med 43: 1164-1169.

256. Dunn J, Qiu H, Kim S, Jjingo D, Hoffman R, et al. (2014) Flowdependent epigenetic DNA methylation regulates endothelial gene expression and atherosclerosis. J Clin Invest 124: 3187-3199.

257. Zhang BK, Lai YQ, Niu PP, Zhao M, Jia SJ1 (2013) Epigallocatechin-3gallate inhibits homocysteine-induced apoptosis of endothelial cells by demethylation of the DDAH2 gene. Planta Med 79: 1715-1719.

258. Kumar A, Kumar S, Vikram A, Hoffman TA, Naqvi A, et al. (2013) Histone and DNA methylation-mediated epigenetic downregulation of endothelial Kruppel-like factor 2 by low-density lipoprotein cholesterol. Arterioscler Thromb Vasc Biol 33: 1936-1942.

259. Li G, Peng J, Liu Y, Li X, Yang Q, et al. (2015) Oxidized low-density lipoprotein inhibits THP-1-derived macrophage autophagy via TET2 down-regulation. Lipids 50: 177-183.

260. Jia L, Zhu L, Wang JZ, Wang XJ, Chen JZ, et al. (2013) Methylation of FOXP3 in regulatory T cells is related to the severity of coronary artery disease. Atherosclerosis 228: 346-352.

261. Chen KC, Wang YS, Hu CY, Chang WC, Liao YC, et al. (2011) OxLDL up-regulates microRNA-29b, leading to epigenetic modifications of MMP-2/MMP-9 genes: a novel mechanism for cardiovascular diseases. FASEB journal : official publication of the Federation of American Societies for Experimental Biology 25: 1718-1728.

262. Wood A, Shilatifard A (2004) Posttranslational modifications of histones by methylation. Adv Protein Chem 67: 201-222.

263. Alkemade FE, van Vliet P, Henneman P, van Dijk KW, Hierck BP, et al. (2010) Prenatal exposure to apoE deficiency and postnatal hypercholesterolemia are associated with altered cell-specific lysine methyltransferase and histone methylation patterns in the vasculature. Am J Pathol 176: 542-548.

264. Wierda RJ, Rietveld IM, van Eggermond MC, Belien JA, van Zwet EW3, et al. (2015) Global histone H3 lysine 27 triple methylation levels are reduced in vessels with advanced atherosclerotic plaques. Life Sci 129: 3-9.

265. Xiao Y, Huang W, Zhang J, Peng C, Xia M, et al. (2015) Increased plasma $\mathrm{S}$-adenosylhomocysteine-accelerated atherosclerosis is associated with epigenetic regulation of endoplasmic reticulum stress in apoE-/- mice. Arteriosclerosis, thrombosis, and vascular biology 35: 60-70.

266. Weng X, Cheng X, Wu X, Xu H, Fang M, et al. (2014) Sin3B mediates collagen type I gene repression by interferon gamma in vascular smooth muscle cells. Biochem Biophys Res Commun 447: 263-270. 
Citation: Fuior EV, Trusca VG, Roman C, Gafencu AV (2015) Enzymatic Targets in Atherosclerosis. J Mol Genet Med 9: 176. doi: 10.4172/1747-0862.1000176

Page 20 of 20

267. Bekkering S, Quintin J, Joosten LA, van der Meer JW, Netea MG, et al. (2014) Oxidized low-density lipoprotein induces long-term proinflammatory cytokine production and foam cell formation via epigenetic reprogramming of monocytes. Arterioscler Thromb Vasc Biol 34: $1731-1738$ 